Research Article

\title{
Optimum Design and Performance of Porous Concrete for Heavy-Load Traffic Pavement in Cold and Heavy Rainfall Region of NE China
}

\author{
Ailing Yao, Hao Ding, Xiaochen Zhang, Zhao Hu ${ }^{(D)}$, Runshu Hao, and Tao Yang \\ School of Highway, Chang'an University, Xi'an 710064, China \\ Correspondence should be addressed to Zhao Hu; huzhao@chd.edu.cn
}

Received 8 October 2017; Revised 25 January 2018; Accepted 26 February 2018; Published 1 April 2018

Academic Editor: Charles C. Sorrell

Copyright (c) 2018 Ailing Yao et al. This is an open access article distributed under the Creative Commons Attribution License, which permits unrestricted use, distribution, and reproduction in any medium, provided the original work is properly cited.

\begin{abstract}
The aim of the study was to solve the problem of drainage stability of pavement base in cold and Cloudburst area. With porous concrete as the research object, an optimum design of porous concrete was determined using a step filling and orthogonal test method, and the relationship between the porosity and the connected porosity of the porous concrete was analyzed. Furthermore, drainage performance and frost resistance of the pavement, compressive strength of the porous concrete, bending strength, and compressive elastic modulus were studied. The results show that the effects of water-cement ratio on the strength of porous concrete based on the step filling method are the most significant. In addition, the connected porosity and goal porosity have a good linear relationship; that is, the drainage performance increases with the increase in connected porosity, whereas the frost resistance, compressive strength, flexural tensile strength, and compressive elastic modulus decrease with the increase in connected porosity. Based on an engineering project in Inner Mongolia (in China), it was shown that porous concrete with a goal porosity of $15 \%$ used as a pavement base could meet the requirements of cold weather, showers, and heavy traffic.
\end{abstract}

\section{Introduction}

In recent years, with the vigorous development of transportation, the scale and standards of highway construction have been continuously improving. In highway construction, a form of semirigid asphalt pavement is the most frequently used material in highway projects [1-3]. This structure has good stability, and it is easy to mechanize the construction and achieve quality control. However, this type of semirigid asphalt pavement tends to have some serious drawbacks. The design of semirigid base asphalt pavement complies with the principle of dense gradation, which is intended to reduce the pavement surface and internal pores to prevent the flow of water. However, not only does such surface not drain, but water entering into the road cannot be promptly ruled out, resulting in water damage, which has become the most important cause of the early damage to road surfaces [4-7]. In addition, semirigid materials are sensitive to temperature changes and prone to temperature shrinkage, resulting in transverse cracks [8-11]. The development of such cracks is influenced from the temperature and load, which eventually act on the surface layer to form reflective cracks. Because the inorganic binder used in semirigid materials has a lower strength that is not up to the standards of rigid materials represented by cement concrete, base cracks or fatigue frequently occurs. Moreover, cracks appear and are reflected on the surface layer, which results in a shedding of the surface material, thereby seriously affecting the lifetime of the pavement [12-15]. Particularly, for roads with heavy traffic under cold weather conditions, the ability of the bearing load, frost resistance, and drainage of the pavement base play a decisive role in the stability of a highway-engineering project. If taking a traditional form (semirigid based with asphalt pavement), the water accessing the pavement structure 
TABLE 1: Summary of test results of coarse aggregate.

\begin{tabular}{|c|c|c|c|c|c|c|c|c|c|}
\hline \multirow{2}{*}{$\begin{array}{l}\text { Aggregate size } \\
(\mathrm{mm})\end{array}$} & \multicolumn{3}{|c|}{ Density $\left(\mathrm{g} / \mathrm{cm}^{3}\right)$} & \multicolumn{2}{|c|}{ Mud content (\%) } & \multicolumn{2}{|c|}{$\begin{array}{c}\text { Needle and plate } \\
\text { particle content }(\%)\end{array}$} & \multicolumn{2}{|c|}{ Crushing value (\%) } \\
\hline & $\begin{array}{c}\text { Apparent } \\
\text { density }\end{array}$ & $\begin{array}{c}\text { Surface dry } \\
\text { density }\end{array}$ & $\begin{array}{l}\text { Bulk volume } \\
\text { density }\end{array}$ & $\begin{array}{l}\text { Test } \\
\text { results }\end{array}$ & $\begin{array}{c}\text { Code } \\
\text { requirement }\end{array}$ & $\begin{array}{l}\text { Test } \\
\text { results }\end{array}$ & $\begin{array}{c}\text { Code } \\
\text { requirement }\end{array}$ & $\begin{array}{c}\text { Test } \\
\text { results }\end{array}$ & $\begin{array}{l}\text { Code } \\
\text { requirement }\end{array}$ \\
\hline $9.5 \sim 13.2$ & 2.833 & 2.813 & 2.802 & 0.8 & \multirow{4}{*}{$\leq 1$} & 9.3 & \multirow{4}{*}{$\leq 15$} & \multirow{4}{*}{8.1} & \multirow{4}{*}{$\leq 28$} \\
\hline $13.2 \sim 16$ & 2.831 & 2.819 & 2.813 & 0.7 & & 7.4 & & & \\
\hline $16 \sim 19$ & 2.835 & 2.819 & 2.811 & 0.5 & & 6.1 & & & \\
\hline $19 \sim 26.5$ & 2.784 & 2.770 & 2.762 & 0.4 & & 3.6 & & & \\
\hline
\end{tabular}

TABLE 2: Summary of test results of cement physical indexes.

\begin{tabular}{|c|c|c|c|}
\hline \multicolumn{2}{|l|}{ Test items } & National standard & Measured value \\
\hline \multirow{2}{*}{\multicolumn{2}{|c|}{$\begin{array}{l}\text { Fineness }(\%) \\
\text { Specific surface area }\left(\mathrm{m}^{2} / \mathrm{kg}\right)\end{array}$}} & $\leq 10.0$ & 0.4 \\
\hline & & $\geq 300$ & 379 \\
\hline \multirow{2}{*}{ Setting time (min) } & Initial setting & $\geq 45$ & 204 \\
\hline & Final setting & $\leq 600$ & 261 \\
\hline \multicolumn{2}{|c|}{ Stability } & Qualified & Qualified \\
\hline \multicolumn{2}{|c|}{$3 \mathrm{~d}$ flexural strength $(\mathrm{MPa})$} & $\geq 3.5$ & 5.0 \\
\hline \multicolumn{2}{|c|}{$3 \mathrm{~d}$ compressive strength $(\mathrm{MPa})$} & $\geq 15.0$ & 23.4 \\
\hline
\end{tabular}

cannot be removed in time, which will incur serious damage to the entire pavement structure [16-19].

Therefore, to ensure the stability of road traffic conditions in cold regions under heavy showers, porous concrete can be used as a pavement base material [20-22]. As a new type of drainage base material, porous concrete is between cement stabilized macadam and ordinary concrete. In 2008, porous concrete was applied to the Olympic project, and the Olympic Water Park was paved with porous concrete, which was combined with other drainage facilities to realize the efficient use of natural precipitation in the park. In 2010, a porous concrete road was paved in the World Expo Park in Shanghai, which has been in good condition so far. Many scholars have done a lot of research on porous concrete and have made remarkable achievements. Zheng analysed the factors affecting the permeability of porous concrete; meanwhile, the test operation and data processing method of porous concrete were proposed [23]. Jiang used digital image processing technology to observe pore size distribution and plane void on porous concrete section. The impact of the void ratio, coarse aggregate size, water-cement ratio on pore size distribution, and plane void were discussed [24]. However, there is a shortage of research on the gradation design and frost resistance of porous concrete. So, this paper, through a large number of experiments, the mixture ratio, drainage performance, frost resistance, and mechanical properties of porous concrete, was studied to obtain the rationality of using porous concrete as a base layer in heavy-load traffic pavement in cold and heavy shower regions.

\section{Mixture Ratio for Porous Concrete}

2.1. Raw Materials. Raw materials are an integral part of the concrete, and its properties determine the performance of concrete to a great extent. Therefore, it is necessary to test the properties of the raw materials [25-27]. The porous concrete contains coarse aggregate, cement, and water; besides, there is no admixture in the test.

2.1.1. Coarse Aggregate. Coarse aggregate is the main component of the skeleton structure of porous concrete and bears a considerable amount of load. Therefore, coarse aggregate should be clean, dry, angular, and close to cube in shape.

In accordance with the relevant test procedures of coarse aggregate [28], after the coarse aggregate used by screening for performance testing, the results are shown in Table 1.

2.1.2. Cement. Cement is an important binder in porous concrete, which plays the role of bonding the structural skeleton formed by coarse aggregate into a whole. It is very important to test the chemical composition and physical index of cement to ensure the performance of porous concrete after forming. According to Test Methods of Cement and Concrete for Highway Engineering [29], all chemical and physical indexes of cement were tested, as shown in Table 2.

After inspection, the quality of the cement can meet the national standard and can be used for the preparation and performance test of the porous concrete specimens.

2.1.3. Water. Water is an important lubricant, which plays a role in promoting the formation of porous concrete, and ordinary tap water can be used for the preparation of porous concrete specimens. It should be noted that the structure of porous concrete is different from the dense structure of ordinary concrete, there are more connected pores, the contact area with the external environment is large, and the evaporation rate of water is fast. Therefore, the control of the water amount in the molding process should be considered specially. 


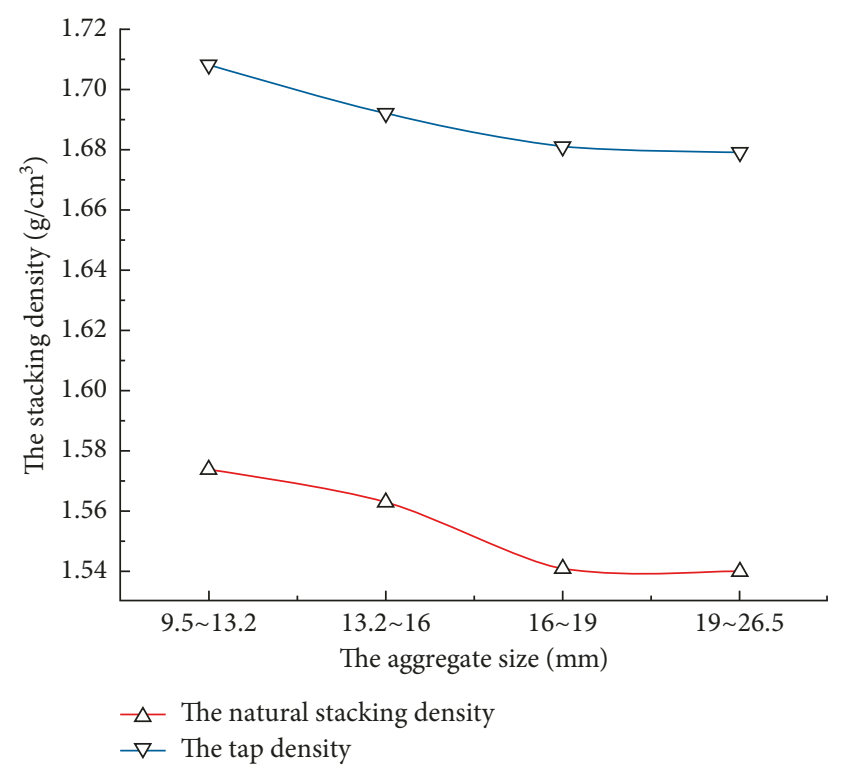

FIGURE 1: Summary of coarse aggregate density of test results.

2.2. Optimization Design of Mineral Composition. The most important features in the composition of porous concrete are a large number of pores and a lack of filler in the mixture. As the optimal composition, the coarse aggregates are intertwined with each other to form a skeleton structure, whereas the aggregate surface is wrapped with cement slurry in a consistent manner. The aggregate is bonded together into a whole through the hydration of the cement slurry to form a porous material having a certain mechanical strength [30-33].

To ensure that the porosity of porous concrete can play a sufficiently important role in the drainage, the nominal maximum size for the coarse aggregates used in the test is 9.5-26.5 $\mathrm{mm}$. Owing to a lack of filling of fine aggregates, the construction of a coarse aggregate skeleton structure and the intercalation friction between aggregate contact points are important guarantees for the formation of the material strength. In this chapter, from the point of view of building aggregate skeleton and improving the contact effectiveness between aggregates, the gradation design method of porous concrete is expounded in accordance with the stage filling theory. The test procedure used is as follows.

2.2.1. Ascertain the Evaluation Index. According to the relevant provisions of the "Test Methods of Aggregate for Highway Engineering" (JTG E42-2005) [28], the natural stacking density and tap density of each type of aggregate are measured to determine the packing mode that is more helpful to the formation of the aggregate skeleton structure. The test results are shown in Figure 1.

As can be seen from the above description, the stacking density of the aggregate can be clearly increased through vibration, with an increase of about $8 \%$. This shows that vibrations can cause coarse aggregates to be squeezed and thereby reach a compact state, forming a more solid skeleton structure and more effective interaggregate contact. In

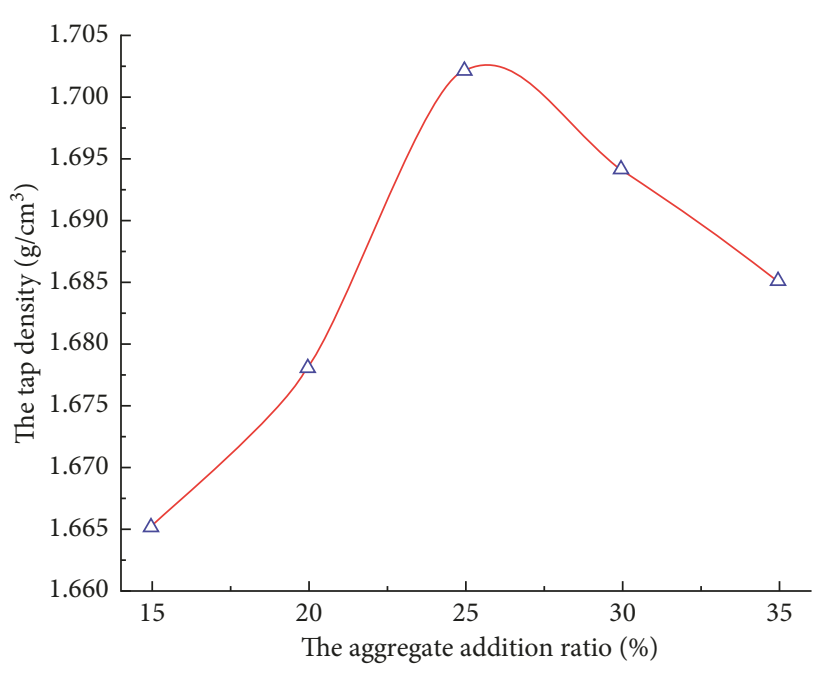

FIGURE 2: First filling results.

addition, the same standard vibration table can be used in the process of measuring the vibration density of the aggregate to avoid the influence of the test equipment on the forming effect of the test piece. Therefore, during the process of determining the optimal gradation of the coarse aggregate, the tap density should be used as an index to evaluate the effects of the aggregate compaction.

2.2.2. First Level Filling. Aggregate with a maximum nominal diameter of $19-26.5 \mathrm{~mm}$ is used as the first stage, whereas the second stage uses aggregate of $16-19 \mathrm{~mm}$. The second batch of aggregates is gradually placed into the first batch at different proportions. After mixing, the tap density of mixed aggregate at different blending ratios is measured, and the maximum ratio of the filling is taken as the optimum filling ratio. The results shown in Figure 2.

2.2.3. Second Level Filling. Aggregates with a nominal maximum diameter of $19-26.5 \mathrm{~mm}$ are mixed with aggregates of $16-19 \mathrm{~mm}$ in diameter at a proportion of $25 \%$, and aggregates with a diameter of $13.2-16 \mathrm{~mm}$ as the third stage are put into the combined aggregate at different proportions. After mixing, the tap density of the mixed aggregates at different blending ratios is measured, and the maximum ratio of the filling is taken as the Optimum filling Rate. The results are shown in Figure 3.

The results show that when the ratio of $13.2-16 \mathrm{~mm}$ aggregates reaches $20 \%$, the tap density of the third stage aggregates is at the largest level.

2.2.4. Third Level Filling. This is the final stage, the steps of which are the same as the previous stage. The results are shown in Figure 4.

In summary, the proportion of each aggregate in the fourth block mixture can be obtained. That is, the proportion of aggregates of $19-26.5,16-19,13.2-16$, and $9.5-13.2 \mathrm{~mm}$ in diameter is $58 \%, 14.5 \%, 14.5 \%$, and $13 \%$, respectively. 


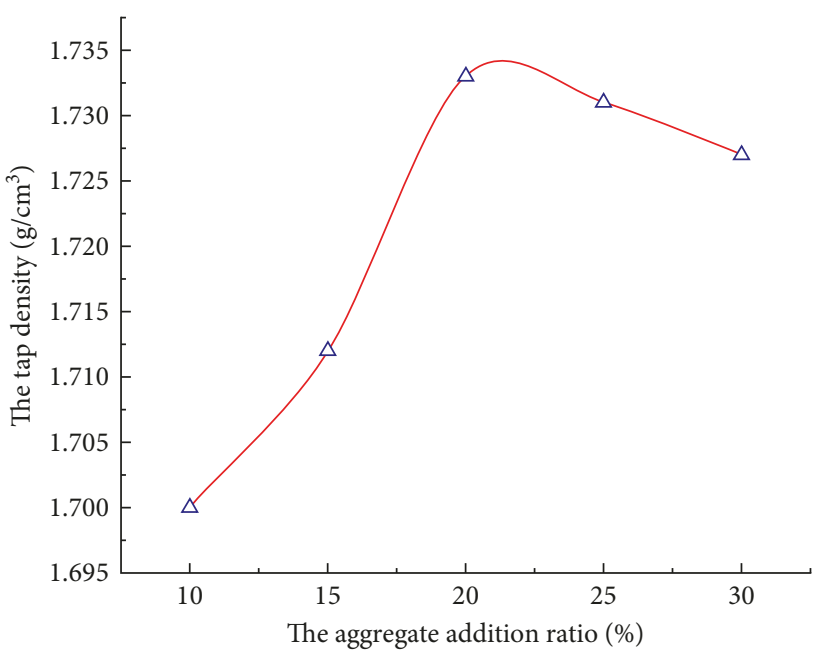

FIGURE 3: Second filling results.

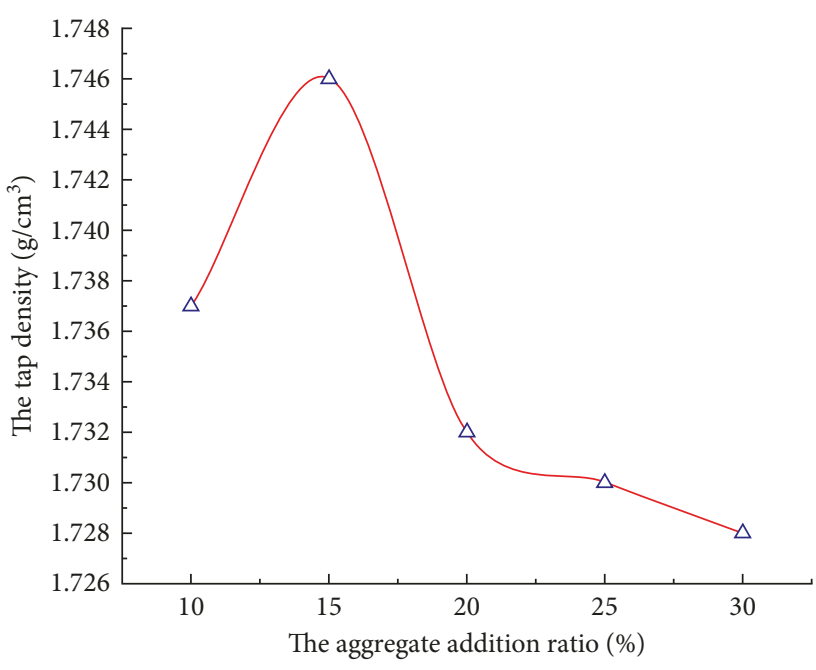

FIgURE 4: Third filling results.

\subsection{Optimum Design of Mix Proportion of Porous Concrete}

2.3.1. Mix Proportion Calculation of Porous Concrete. After mixing the aggregate in different stages based on the abovementioned description, the density of the aggregate is measured to calculate the porosity according to the "Test Methods of Aggregate for Highway Engineering" (TG E422005) [16]. The results are presented in Table 3.

The purpose of designing a mixture ratio of porous concrete is to effectively control the postmoulding specimen (connected) based on the known design parameters through calculations. The ratio of porous concrete is calculated using the unit volume method as follows:

$$
\begin{aligned}
m_{\mathrm{g}} & =0.98 \rho, \\
V_{\mathrm{c}+\mathrm{w}} & =P^{\prime}-P,
\end{aligned}
$$

where $m_{\mathrm{g}}$ is the cubic mass of the aggregate in porous concrete, $V_{\mathrm{c}+\mathrm{w}}$ is the cubic volume of cement slurry in porous concrete, $P$ is the goal porosity, $P^{\prime}$ is the void fraction of the aggregate, $\rho$ is the tap density $\left(1.746 \mathrm{~g} / \mathrm{cm}^{3}\right), m_{\mathrm{c}}$ is the mass of the concrete, $\rho_{\mathrm{c}}$ is the density of the concrete $\left(3.15 \mathrm{~g} / \mathrm{cm}^{3}\right), m_{\mathrm{w}}$ is the mass of the water, and $\rho_{\mathrm{w}}$ is density of the water. The following can then be obtained:

$$
\frac{m_{\mathrm{c}}}{\rho_{\mathrm{c}}}+\frac{m_{\mathrm{w}}}{\rho_{\mathrm{w}}}=P^{\prime}-P
$$

Therefore, it is only necessary to determine the ratio of cement to water in the cement slurry, which is called the water-cement, or w/c, ratio. According to (1) and (2), the quality of each component in the unit volume of porous concrete can be calculated.

\subsubsection{Determination of $w / c$ Ratio and Mixing and Vibration} Times. To ensure that porous concrete has a superior performance and to improve its strength, the thickness and consistency of the cement slurry should be suitable for concrete [34, 35]. Thinner coating layers and greater consistency make it difficult to form a comprehensive aggregate package, and thus the bonding action of the slurry will not be adequately developed, resulting in an insufficient strength of the concrete. A thicker coating and lesser consistency result in a dripping of the excess slurry, which accumulates at the bottom of the concrete, destroying the original pore structure, and lowering the performance of porous concrete drainage [36]. Thus, the amount and consistency of the cement slurry must be controlled strictly during the specimen moulding process to make sure that the specimen achieves a good performance level after formation. Based on the aggregate gradation, the concrete type and specimen formation method are determined, and the moulding quality of the mixture is controlled from three aspects: the w/c ratio and mixing and vibration times.

The standard JTG E51-2009 [37] has indicated that the cement-concrete mixing time is generally $2 \mathrm{~min}$ and that the vibration time is no more than $90 \mathrm{~s}$, which is typical for ordinary concrete; however, the special structural characteristics of porous concrete were not considered. Therefore, for porous concrete, the appropriate $\mathrm{w} / \mathrm{c}$ ratio and mixing and vibration times should be determined through testing. However, considering the comprehensive influence of each factor in porous concrete, the factors need to be accurately determined while appropriately reducing the number of tests. An orthogonal test design based on mathematical statistics has been applied [38]. Orthogonal experimental design is a design method to study multiple factors and levels; it is based on the orthogonality from the comprehensive test selected some representative points of the experiment, these representative points with a "uniform dispersion, neat comparable" characteristics, is a high efficiency, rapid, economical experimental design method. The level of orthogonal test factors is shown in Table 4.

According to the selected factors and levels, the level of orthogonal testing is determined as follows: L16 $\left(3^{4}\right)$ including $\mathrm{A}_{1} \mathrm{~B}_{1} \mathrm{C}_{1}, \mathrm{~A}_{2} \mathrm{~B}_{2} \mathrm{C}_{2}, \mathrm{~A}_{3} \mathrm{~B}_{3} \mathrm{C}_{3}, \mathrm{~A}_{4} \mathrm{~B}_{4} \mathrm{C}_{4}, \mathrm{~A}_{2} \mathrm{~B}_{1} \mathrm{C}_{2}, \mathrm{~A}_{2} \mathrm{~B}_{2} \mathrm{C}_{1}$, $\mathrm{A}_{2} \mathrm{~B}_{3} \mathrm{C}_{4}, \mathrm{~A}_{2} \mathrm{~B}_{4} \mathrm{C}_{3}, \mathrm{~A}_{3} \mathrm{~B}_{1} \mathrm{C}_{3}, \mathrm{~A}_{3} \mathrm{~B}_{2} \mathrm{C}_{4}, \mathrm{~A}_{3} \mathrm{~B}_{3} \mathrm{C}_{1}, \mathrm{~A}_{3} \mathrm{~B}_{4} \mathrm{C}_{2}, \mathrm{~A}_{4} \mathrm{~B}_{1} \mathrm{C}_{4}$, $\mathrm{A}_{4} \mathrm{~B}_{2} \mathrm{C}_{3}, \mathrm{~A}_{4} \mathrm{~B}_{3} \mathrm{C}_{2}, \mathrm{~A}_{4} \mathrm{~B}_{4} \mathrm{C}_{1}$, which are applied 16 times. To 
TABLE 3: Characteristics of mixed aggregate of porous concrete.

\begin{tabular}{lccc}
\hline Apparent density $\left(\mathrm{g} / \mathrm{cm}^{3}\right)$ & Surface dry density $\left(\mathrm{g} / \mathrm{cm}^{3}\right)$ & Bulk volume density $\left(\mathrm{g} / \mathrm{cm}^{3}\right)$ & Void ratio $(\%)$ \\
\hline 2.778 & 2.767 & 2.760 & 37.150 \\
\hline
\end{tabular}

TABLE 4: Factor level table of orthogonal test.

\begin{tabular}{lccc}
\hline Level & & Factor & \\
& Water-cement ratio A & Mixing time B (s) & Vibration time C (s) \\
\hline 1 & 0.30 & 60 & 10 \\
2 & 0.28 & 50 & 20 \\
3 & 0.26 & 40 & 30 \\
4 & 0.24 & 30 & 40 \\
\hline
\end{tabular}

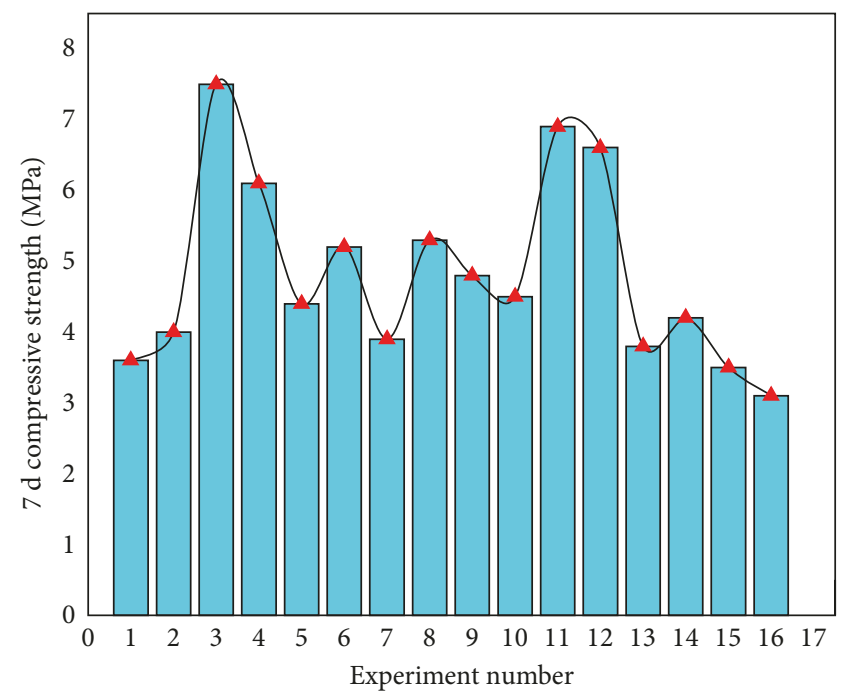

FIgURE 5: Results of orthogonal test.

accurately obtain the experimental control parameters of porous concrete suitable for each goal porosity, porous concrete with the largest amount of cement $15 \%$ of the goal porosity) was selected as the test object. The mixture ratio was calculated, and the $7 \mathrm{~d}$ compressive strength was applied as the test analysis index, as shown in Figure 5. Through a range analysis, the influence of each factor on the test results was determined, and the optimum combination scheme was obtained, as shown in Table 5.

In the table, $\mathrm{I}_{j}-\mathrm{IV}_{j}$ is the sum of the numerical values corresponding to each level in column J, and $K_{j}$ is the number of occurrences of column $J$ at the same level and is equal to the number of tests $n(n=16)$ divided by the level number. In addition, $\mathrm{I}_{j} / k_{j}-\mathrm{IV}_{j} / k_{j}$ is the average of each level in column $\mathrm{J}$ of the test index, and $D_{j}$ is the difference between the maximum and minimum of the corresponding averages in column $\mathrm{J}$.

Through a range analysis, the impact level of each factor on the test index is as follows: factor $\mathrm{A}$ (w/c ratio) is the largest, factor B (mixing time) is the second largest, and factor $\mathrm{C}$ (vibration time) is the smallest. The optimum combination is $\mathrm{A}_{3} \mathrm{~B}_{3} \mathrm{C}_{3}$ when the w/c ratio is 0.26 , mixing time is $40 \mathrm{~s}$, and vibration time is $30 \mathrm{~s}$.
Based on the results of the orthogonal test, the mass of each component per unit volume of porous concrete can be calculated, as shown in Table 6.

\section{Relationship and Comparison between Porosity and Connected Porosity}

In appearance, porous concrete has numerous pores and a large aperture size. In fact, it is similar to other highway materials $[39,40]$ and has three types of porosities.

(1) Closed pores. These pores do not connect with the external environment, mainly owing to the internal closed pores in the aggregate and the bubbles produced through an uneven mixing during the sample formation. A large number of closed pores will have an adverse effect on the strength of the material, and the pores lose the function of draining. Therefore, closed pores are useless for drainage purposes.

(2) Open pores. These pores are interlinked with the external environment. The results indicate that such porosity has no substantive effect on the drainage of porous concrete.

(3) Connected pores. These pores penetrate the inner material, and a skeleton structure is formed with mutual friction between the aggregates. Both ends of the connected pores are in contact with the external environment and become an effective drainage channel within porous concrete. Thus, to verify the drainage performance of porous concrete materials, the connected porosity is simply measured.

The connected porosity of the specimen is controllable after moulding, which is not only the requirement of the mixture design, but also the premise for porous concrete in providing a full range of performance advantages. According to the porous concrete specimens required for the experiment, standard specimens with dimensions of $150 \mathrm{~mm} \times 150 \mathrm{~mm} \times 150 \mathrm{~mm}$ were made to meet the $7 \mathrm{~d}$ curing period and $28 \mathrm{~d}$ of anticompression strength testing, and the experimental results were plotted into a histogram with error bars, as shown in Figures 6 and 7.

A standard specimen of $100 \mathrm{~mm} \times 100 \mathrm{~mm} \times 400 \mathrm{~mm}$ in size was also designed for the antifreezing test to meet the $7 \mathrm{~d}$ 
TABLE 5: Range analysis of orthogonal test.

\begin{tabular}{lcccccccccc}
\hline \multirow{2}{*}{ Column number } & \multicolumn{1}{c}{ Analysis index } \\
& $\mathrm{I}_{j}$ & $\mathrm{II}_{j}$ & $\mathrm{III}_{j}$ & $\mathrm{IV}_{j}$ & $k_{\mathrm{j}}$ & $\mathrm{I}_{j} / k_{\mathrm{j}}$ & $\mathrm{II}_{j} / k_{\mathrm{j}}$ & $\mathrm{III}_{j} / k_{j}$ & $\mathrm{IV}_{j} / k_{j}$ & $D_{j}$ \\
\hline 1 & 21.2 & 18.8 & 22.8 & 14.6 & 4 & 5.2 & 4.7 & 5.7 & 3.65 \\
2 & 16.6 & 17.9 & 21.8 & 21.1 & 4 & 4.15 & 4.75 & 5.45 & 5.275 \\
3 & 18.8 & 18.5 & 21.8 & 18.3 & 4 & 4.7 & 4.625 & 5.45 & 4.575 & 0.875 \\
\hline
\end{tabular}

TABLE 6: The result of design of mix proportion of porous concrete (per cubic meter).

\begin{tabular}{|c|c|c|c|c|c|c|}
\hline $\begin{array}{l}\text { Goal porosity } \\
(\%)\end{array}$ & $\begin{array}{l}\text { Quality of coarse aggregate } \\
(\mathrm{kg})\end{array}$ & $\begin{array}{l}\text { Water quality } \\
(\mathrm{kg})\end{array}$ & $\begin{array}{c}\text { Cement quality } \\
(\mathrm{kg})\end{array}$ & $\begin{array}{c}\text { Water-cement } \\
\text { ratio }\end{array}$ & $\begin{array}{l}\text { Mixing time } \\
(\mathrm{s})\end{array}$ & $\begin{array}{l}\text { Vibration time } \\
\text { (s) }\end{array}$ \\
\hline 15 & \multirow{4}{*}{1711} & 99 & 380 & \multirow{4}{*}{0.26} & \multirow{4}{*}{40} & \multirow{4}{*}{30} \\
\hline 20 & & 76 & 294 & & & \\
\hline 25 & & 54 & 208 & & & \\
\hline 30 & & 32 & 123 & & & \\
\hline
\end{tabular}

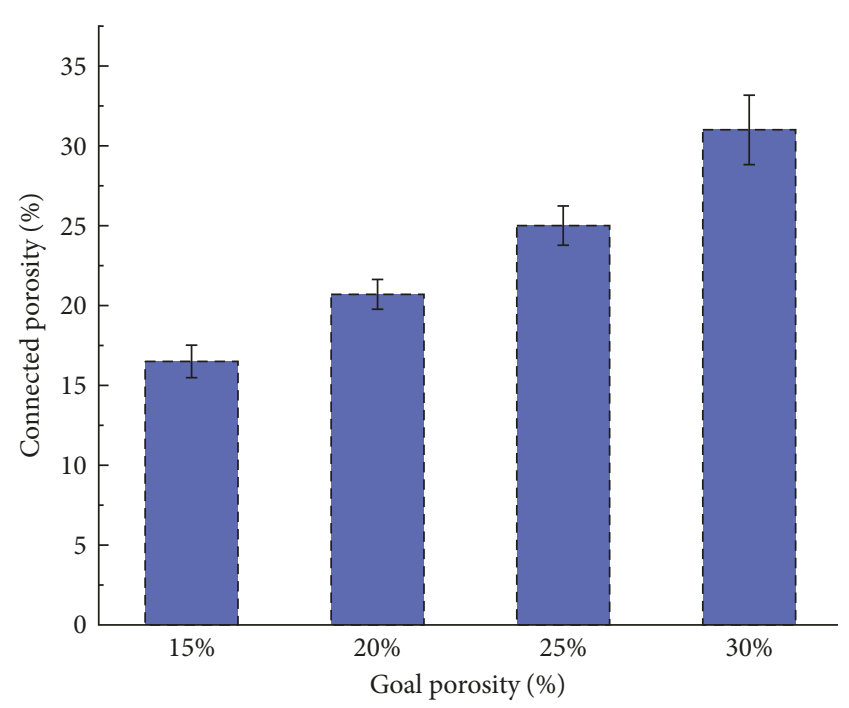

Figure 6: Test results of $150 \mathrm{~mm} \times 150 \mathrm{~mm} \times 150 \mathrm{~mm}(7 \mathrm{~d})$.

curing period and $28 \mathrm{~d}$ of flexural tensile strength testing. Standard specimens of $150 \mathrm{~mm} \times 150 \mathrm{~mm} \times 300 \mathrm{~mm}$ were also created to meet the curing period for the $90 \mathrm{~d}$ anticompression elasticity testing. Finally, standard specimens of $150 \mathrm{~mm} \times 150 \mathrm{~mm} \times 550 \mathrm{~mm}$ were generated made to meet the curing period for the $28 \mathrm{~d}$ permeability performance testing of porous concrete. The results are shown in Tables 7-9.

The size and period of the specimens suitable for each test were determined, the relationship between the connected porosity and goal porosity was analysed, and the feasibility of predicting the porosity was determined based on the goal porosity. It can be seen from the figure that the difference between the individual porosity data and the goal porosity is about $3 \%$, which is larger than those in other specimens. The reason for such a difference is that, with an increase in the size of the specimen, the difficulty in controlling the formation process also increases. However, for the arithmetic average of each set of data, the measured porosity is close to the goal porosity. In other words, the connected porosity and goal porosity of porous concrete

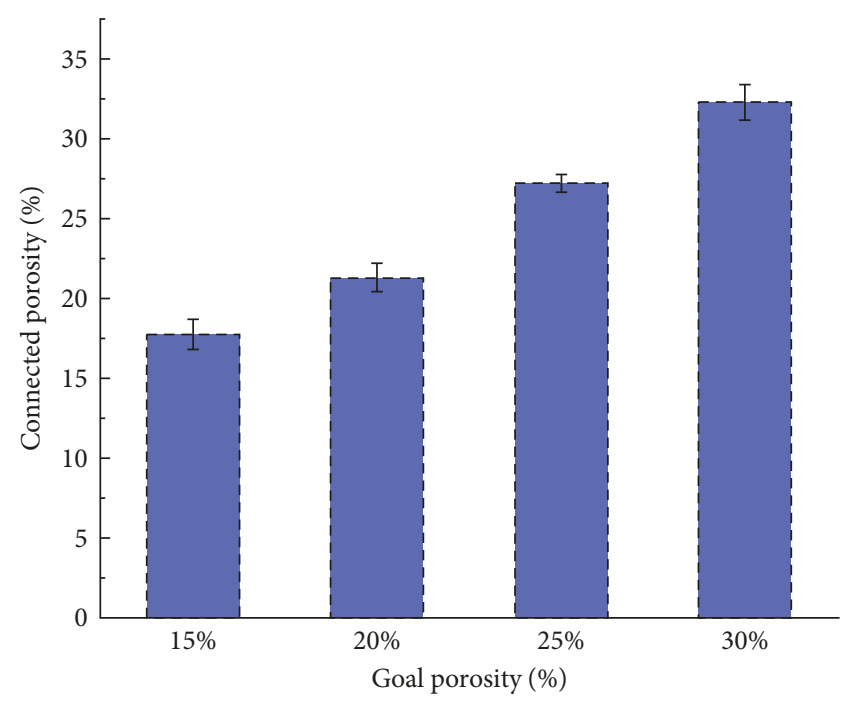

Figure 7: Test results of $150 \mathrm{~mm} \times 150 \mathrm{~mm} \times 150 \mathrm{~mm}(28 \mathrm{~d})$.

have a good linear relationship unrelated to the size and period of the specimens. According to this result, connected pores can be predicted based on the goal porosity in the mixture ratio design.

\section{Study on Pavement Performance of Porous Concrete}

The road performance depends on whether the material can withstand the external environment such as the load, temperature, and precipitation while maintaining the original characteristics. A good road performance means that the materials can prolong the road service life and improve the ride comfort and safety. Porous concrete is different from ordinary compact concrete because of a large number of connected pores that are spread throughout the inside of the material [41, 42]. The existence of these connected pores is beneficial to the drainage and also restricts the strength of the material. Therefore, if the connected porosity is maintained, the pavement performance of porous concrete can be 
TABLE 7: Test results of specimen with $150 \mathrm{~mm} \times 150 \mathrm{~mm} \times 400 \mathrm{~mm}$.

\begin{tabular}{|c|c|c|c|c|c|}
\hline \multirow{2}{*}{ Goal porosity (\%) } & \multicolumn{4}{|c|}{ Flexural tension experiment } & \multirow{2}{*}{$\begin{array}{l}\text { Antifreeze experiment } \\
\text { Connected porosity (\%) }\end{array}$} \\
\hline & Curing period $(\mathrm{d})$ & Connected porosity (\%) & Curing period $(\mathrm{d})$ & Connected porosity (\%) & \\
\hline \multirow{3}{*}{15} & & 17.3 & & 16.4 & 14.8 \\
\hline & 7 & 15.8 & 28 & 17.0 & 15.8 \\
\hline & & 14.4 & & 14.9 & 18.3 \\
\hline \multirow{3}{*}{20} & & 23.3 & & 21.9 & 21.2 \\
\hline & 7 & 21.5 & 28 & 21.7 & 22.8 \\
\hline & & 19.1 & & 23.5 & 23.1 \\
\hline \multirow{3}{*}{25} & & 26.1 & & 26.4 & 27.3 \\
\hline & 7 & 26.4 & 28 & 27.8 & 25.3 \\
\hline & & 25.6 & & 24.9 & 24.9 \\
\hline \multirow{3}{*}{30} & & 30.6 & & 31.9 & 31.3 \\
\hline & 7 & 29.0 & 28 & 31.3 & 29.5 \\
\hline & & 32.0 & & 32.0 & 32.0 \\
\hline
\end{tabular}

TABLE 8: Test results of specimen with $150 \mathrm{~mm} \times 150 \mathrm{~mm} \times 300 \mathrm{~mm}$.

\begin{tabular}{lcc}
\hline \multirow{2}{*}{ Goal porosity (\%) } & $\begin{array}{c}\text { Connected porosity } \\
1(\%)\end{array}$ & $\begin{array}{c}\text { Connected porosity } \\
2(\%)\end{array}$ \\
\hline \multirow{3}{*}{15} & 17.1 & 16.4 \\
& 16.8 & 14.6 \\
& 18.1 & 13.4 \\
20 & 20.6 & 22.7 \\
& 22.1 & 21.3 \\
& 19.3 & 18.9 \\
25 & 23.7 & 23.6 \\
& 27.4 & 27.6 \\
& 25.1 & 26.2 \\
30 & 31.8 & 30.9 \\
& 31.5 & 32.4 \\
\end{tabular}

TABLE 9: Test results of specimen with $150 \mathrm{~mm} \times 150 \mathrm{~mm} \times 550 \mathrm{~mm}$.

\begin{tabular}{lc}
\hline Goal porosity (\%) & Connected porosity $1(\%)$ \\
\hline \multirow{3}{*}{15} & 17.0 \\
& 13.9 \\
& 16.8 \\
20 & 20.9 \\
& 22.2 \\
25 & 21.7 \\
& 26.6 \\
& 23.9 \\
30 & 25.8 \\
& 28.8 \\
\end{tabular}

guaranteed. Meanwhile, the relationship between the connected porosity and road performance was also analysed, and an effective prediction of the road performance was realised, which will be of great benefit to the popularization and application of this type of material $[8,43]$.

4.1. Drainage Performance Test. At present, a constant water head or varying head test usually applies Darcy's law to test

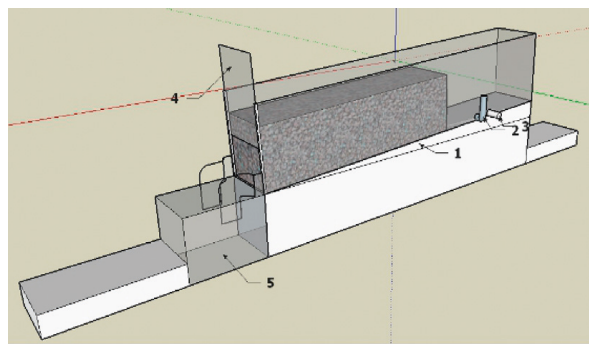

FIgURE 8: Schematic diagram of water permeability of porous concrete.

the drainage performance of a pavement material. However, these two methods have three shortcomings: (1) a difficulty with test control, (2) a small specimen size and discrete test results, and (3) a lack of consideration regarding the influence of the transverse slope on the drainage performance of porous concrete.

To solve the above problems, porous concrete drainage and frost resistance test methods were determined using proprietary patents based on the standard provisions. The tests were carried out using a self-made tester that applies road materials to test the drainage performance (shown in Figures 8 and 9). This tester is an analogue device for testing pavement and can simulate different types of cross slopes based on the test requirements. In addition, it uses the antibending strength of the larger sized standard specimen $(150 \mathrm{~mm} \times 150 \mathrm{~mm} \times 55 \mathrm{~mm})$ for the testing to ensure an adequate seepage path.

Before testing, four sides of the test piece should be sealed to ensure that the pervious sections to be tested are only the front and back and that the drainage path has only a horizontal path. The permeable coefficient of porous concrete is calculated as follows:

$$
K=\frac{Q L}{A t\left(h_{2}-h_{1}\right)},
$$

where $K$ is the coefficient of porous concrete $(\mathrm{cm} / \mathrm{s})$; $Q$ is the amount of water seeping out at time $t\left(\mathrm{~cm}^{3}\right) ; L$ is the seepage length, which is the length of the specimen $(\mathrm{cm}) ; A$ is the seepage area $\left(\mathrm{cm}^{2}\right)$ and, considering the capacity of the maximum drainage capacity, is the cross-sectional area of 


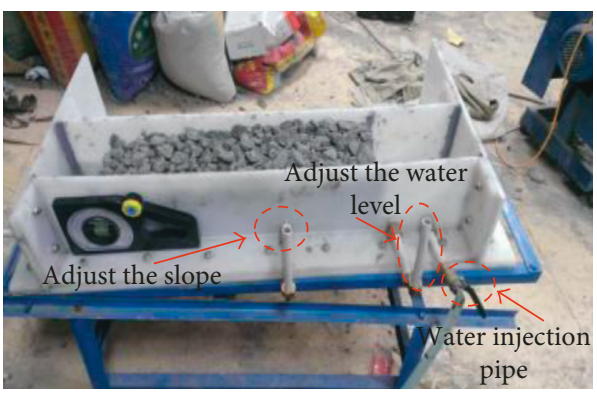

FIGURE 9: Device diagram of testing water permeability of porous concrete.

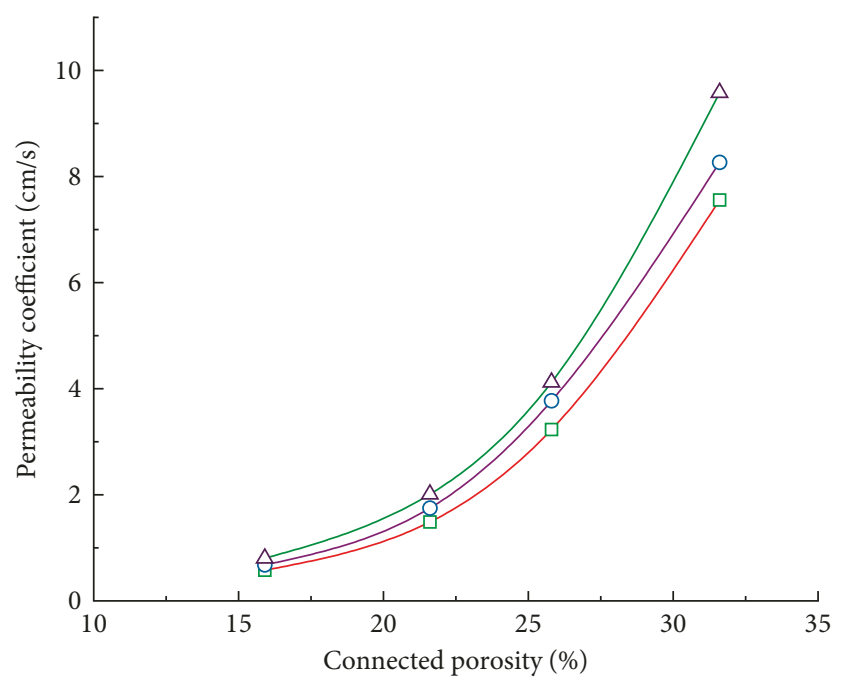

$\neg-$ The cross slope of pavement with $2 \%$

- - The cross slope of pavement with $3 \%$

$-\checkmark$ The cross slope of pavement with $4 \%$

Figure 10: Test results of drainage performance.

the specimen; and $h_{1}-h_{2}$ is the difference between the water head $(\mathrm{cm})$. Because the road surface slope in the simulation is relatively small, the calculation of the specimen height is approximately $15 \mathrm{~cm}$. Finally, $t$ is the permeation time. The results of the drainage performance test of each specimen are shown in Figure 10.

It can be seen that the permeability coefficient of porous concrete is positively related to the cross slope of the pavement. With the increase in slope, the permeability coefficient increases linearly. Based on the distance between curves, the spacing between the two adjacent curves increases gradually, indicating that the permeability coefficient of porous concrete increases gradually with the increase in the connected porosity. With the increase in connected porosity, the drainage performance of porous concrete can improve significantly. Because connected pores play a limited role in the strength and frost resistance of porous concrete, these factors should be taken into consideration when determining the connected porosity.

4.2. Frost Resistance Test. According to the requirements of the specimen formations [37], experiments were carried out

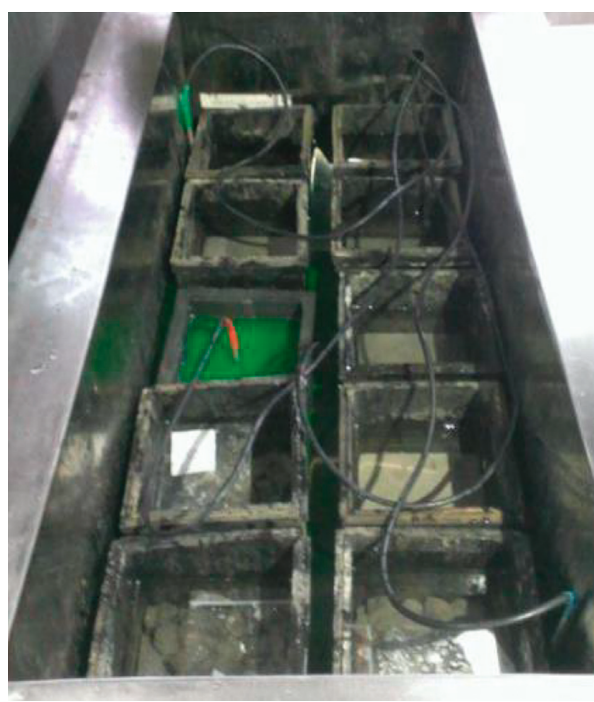

Figure 11: Frost resistance test.

when the regimen reached the prescribed age using an automatic freeze-thawing device. In the first $4 \mathrm{~d}$ of the prescribed age, the specimen is soaked into the $20^{\circ} \mathrm{C} \pm 2^{\circ} \mathrm{C}$ saturated lime water, the specimen surface is dried after soaking is finished, and the test case is loaded into the rubber test box and filled with water. The device is shown in Figure 11. In the experiment, each freeze-thaw cycle should be completed in $2 \mathrm{~h} \sim 5 \mathrm{~h}$, and the central temperature of the specimen during freezing and thawing should be kept in $-18^{\circ} \mathrm{C} \pm 2^{\circ} \mathrm{C}$ and $5^{\circ} \mathrm{C} \pm 2^{\circ} \mathrm{C}$. In this experiment, only weighing, but not calculating the relative dynamic modulus of the specimen, was done. When the quality loss of the specimen is over $5 \%$, the cycle times of the specimen with the last weighing are taken as the maximum antifreeze cycle times.

The relationship between the maximum cycle time of freeze-thawing and the porosity of the porous concrete was determined based on the test results, as shown in Figure 12.

The results indicate that the frost resistance of porous concrete is negatively correlated with its connected porosity. When the connected porosity of the specimen increased from $16.3 \%$ to $29.5 \%$, the maximum number of frost resistance cycles decreased from 65 to 10 , which is a decrease of about $85 \%$, thereby showing a clear downward trend. To further analyse the change in quality of each porosity specimen during the test process, the quality of each specimen before the freeze-thawing cycles was compared with the quality after the freeze-thawing cycles. In addition, after ten freeze-thawing cycles, the change in porosity of the specimen with a goal porosity of $30 \%$ exceeded $5 \%$, the test is over by specification, and the relationship between the cycle time of freeze-thawing and the rate of mass change is not plotted. The result is shown in Figure 13.

The results indicate that with an increase in the number of freeze-thawing cycles, the rate of mass loss of the porous concrete specimens accelerated. As shown in Figure 13, when the number of freeze-thawing cycles increased from 10 to 40 , the adjacent slope between them increased continuously, whereas when the number of freeze-thawing cycles increased from 40 to 60 , the adjacent slope between them 


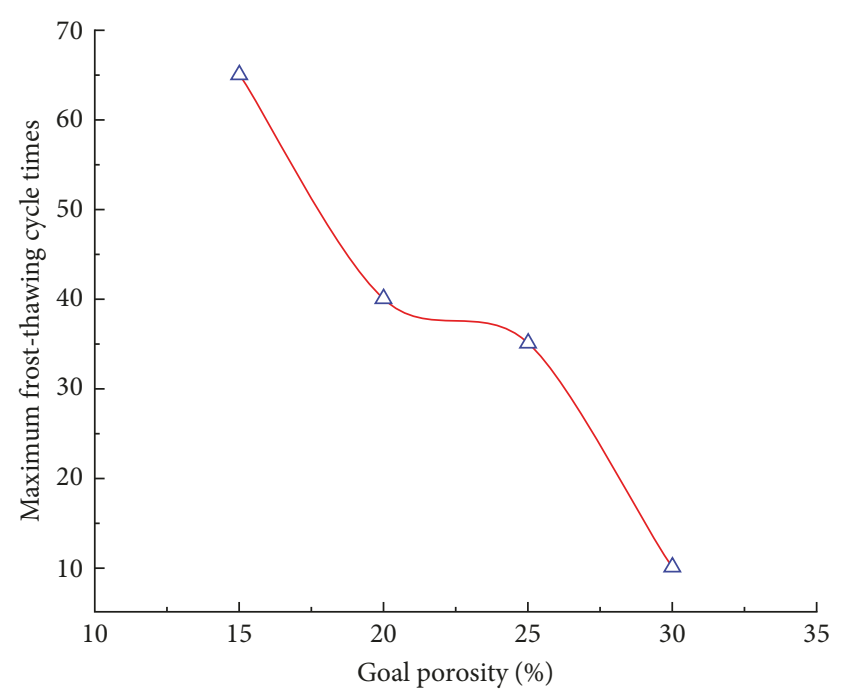

FIGURE 12: Relationship between the maximum cycle time of freeze-thawing and the porosity of the porous concrete.

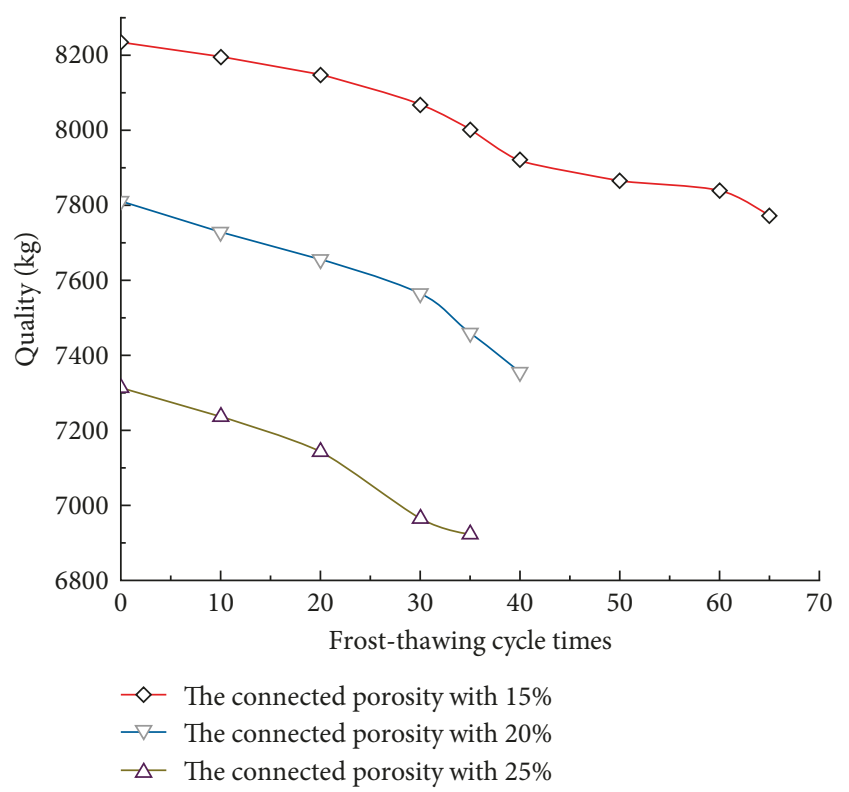

FIGURE 13: Relationship between quality and maximum frostthawing cycle times.

was more gentle initially, but then rapidly increased. The reason for this phenomenon is that during an early antifreeze cycle, the effective connection between the cement stone is destroyed and microcracks are produced, and thus the mass loss of the specimen is mainly caused by the spalling of the hardened cement slurry. As the freezethawing cycles continue, the microcracks in the porous concrete develop rapidly. At this stage, the destruction of the porous concrete is mainly due to the development of cracks. Finally, the cracks extend throughout the entire specimen, causing the specimen to be quickly destroyed.

A microscopic study [44] has shown that the freezethawing damage of concrete is an on-going physical process.

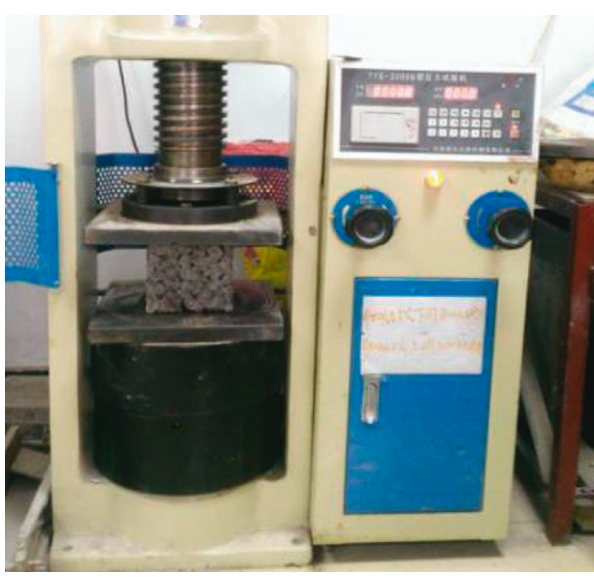

Figure 14: Compressive strength test.

The freeze-thawing cycle gradually makes the structure of the hydration products in concrete become increasingly loose, accompanied by the generation and development of microcracks [45]. With an increase in the number of freezethawing cycles, the microcracks increase and are eventually found throughout the entire structural system, resulting in a cracking of the concrete.

\section{Mechanical Property Test}

As a road material, porous concrete should have sufficient strength and stiffness, and its mechanical properties must be tested [46]. According to the requirements of the specification, combined with the structural characteristics of porous concrete, the compressive strength test, flexural tensile strength test, and compressive modulus test were carried out to obtain the effect of the porous concrete connected porosity on its mechanical properties [47].

5.1. Analysis of Relation between Connected Porosity and Compressive Strength. In accordance with the provisions of the standard $150 \mathrm{~mm} \times 150 \mathrm{~mm} \times 150 \mathrm{~mm}$ specimens and curing until a specified age, the compressive strength was determined, as shown in Figures 14 and 15.

The results show that the $7 \mathrm{~d}$ compressive strength of porous concrete is $2-8 \mathrm{MPa}$, and its $28 \mathrm{~d}$ compressive strength is 3-12 MPa. Additionally, the compressive strength of the porous concrete basically forms during the $7 \mathrm{~d}$ period, reaching about $70 \%$ of the strength at $28 \mathrm{~d}$. Thus, when the conditions are limited, this relationship can be used to predict the compressive strength at $28 \mathrm{~d}$ based on the compressive strength at $7 \mathrm{~d}$. Meanwhile, $7 \mathrm{~d}$ is the major stage of the formation of the compressive strength of porous concrete, and thus the stability of the environment for preserving the health of the material should be guaranteed.

5.2. Analysis of Relation between Connected Porosity and Flexural Tensile Strength. The flexural tensile strength, an important parameter in a pavement structure design, is the maximum flexural load that concrete can bear before breaking, representing the ability of the material to resist 


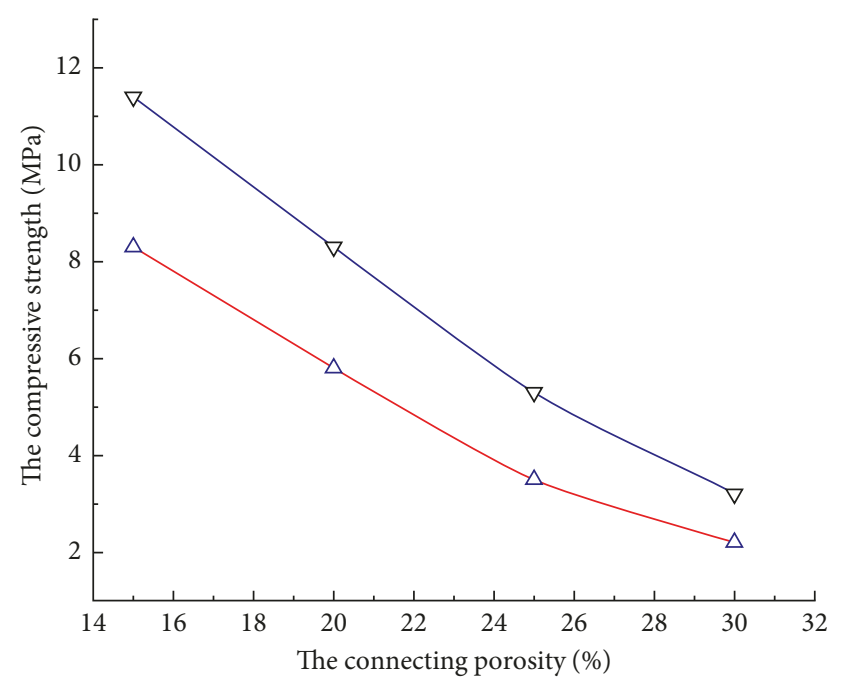

$\triangle$ The compressive strength of $7 \mathrm{~d}$

$\rightarrow-$ The compressive strength of $28 \mathrm{~d}$

FIgURE 15: Relationship between connected porosity and compressive strength.

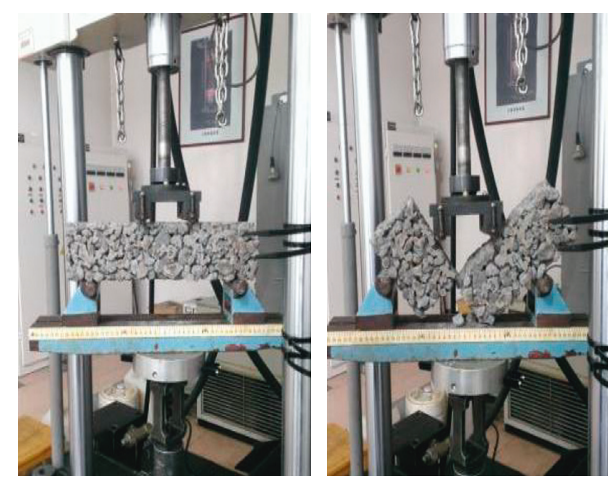

FIgURE 16: Flexural tensile strength tests.

bending. The connected porosity and flexural tensile strength of standard specimens $(100 \mathrm{~mm} \times 100 \mathrm{~mm} \times 400 \mathrm{~mm})$ were measured. As shown in Figures 16 and 17.

According to the analysis data, the flexural tensile strength of porous concrete is sharply lower than its compressive strength, and the $7 \mathrm{~d}$ flexural tensile strength is $0.2-0.9 \mathrm{MPa}$ and the $28 \mathrm{~d}$ flexural tensile strength is $0.3-$ 1.7 MPa. Similar to the compressive strength, the flexural tensile strength of porous concrete is mainly formed during the $7 \mathrm{~d}$ period, reaching about $70 \%$ of the strength at $28 \mathrm{~d}$, as already reported by other authors [48-51]. Furthermore, the connected porosity is a significant factor affecting the flexural tensile strength of porous concrete, and the flexural tensile strength decreases with an increase in this porosity.

5.3. Analysis of Relation between Connected Porosity and Compressive Elastic Modulus. The connection porosity and the compressive elastic modulus test are shown in Figure 18. The experiment results of the compressive elastic modulus of

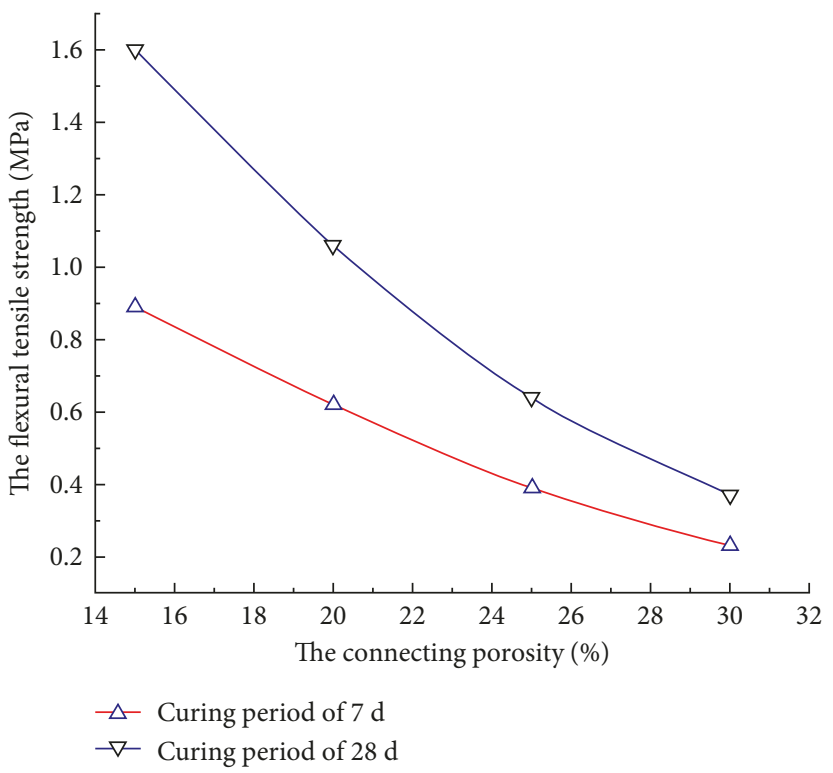

Figure 17: Relationship between connected porosity and flexural tensile strength.

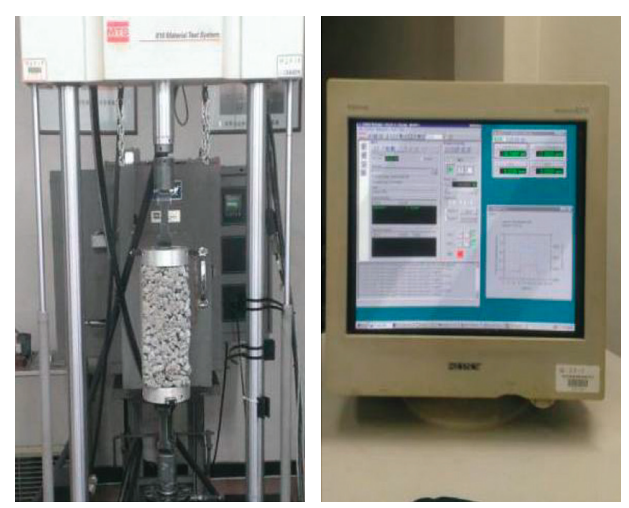

FIGURE 18: Test of compressive elastic modulus.

porous concrete were calculated using the following formula, and the test results are summarized in Figure 19.

$$
E_{\mathrm{c}}=\frac{F_{\mathrm{a}}-F_{0}}{A} \times \frac{L}{\Delta n},
$$

where $E_{\mathrm{c}}$ is the compressive elastic modulus of concrete $(\mathrm{MPa}) ; F_{\mathrm{a}}$ is the final load $(\mathrm{N}), F_{0}$ indicates the initial load, $L$ is the distance between specimens ( $\mathrm{mm}), A$ is the bearing area of a specimen $\left(\mathrm{mm}^{2}\right)$, and $\Delta n$ is the average differential deformation of a specimen during the last loading under the actions of $F_{\mathrm{a}}$ and $F_{0}$.

The experiment data show that the compressive elastic modulus of porous concrete is mainly between 7,500 and $16,000 \mathrm{MPa}$, which indicates a clear rigidity. The compressive elastic modulus of porous concrete decreases with the increase in connected porosity, which is mainly related to the amount of cement. In addition, with the increase in connected porosity and the decrease in cement content, the thickness of the cement paste wrapped over the aggregate 


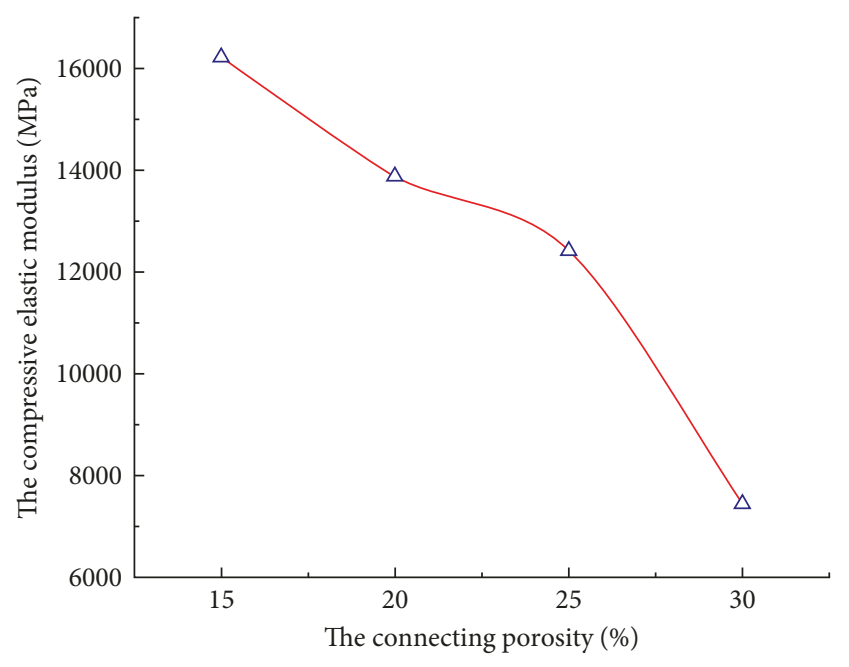

Figure 19: Relationship between connected porosity and compressive elastic modulus.

surface will decrease, and the stiffness of the specimen and the compressive modulus of the resilience will decrease.

\section{Application of Porous Concrete Base in Heavy-Load Traffic Pavement in Cold and Heavy Shower Regions}

6.1. Original Pavement Structure. This study relied on the first-class highway engineering project located in Hulun Buir city of the Inner Mongolia Autonomous Region, which belongs to the $\mathrm{VI}_{1}$ natural highway zoning. There are large reserves of crushed stone in the route area, and the subgrade is dry and wet. Hulun Buir is located in a continental temperate zone with a monsoon climate, with long, freezing winters; frequent cold air motion; deep snow; and long snow cover periods. Additionally, the average temperature annually is $0.1^{\circ} \mathrm{C}$, the standard freezing depth is $2.8 \mathrm{~m}$, and the minimum thickness of the frost protection layer is $70 \mathrm{~cm}$.

Depending on the road traffic load and the topography, geology, meteorology, and hydrology, to determine the design parameters of each structural layer, the local design adopted a semirigid base asphalt pavement structure. The deflection value, allowable tensile stress, and bottom tensile stress of various structural surfaces of the pavement were designed. Finally, the designed deflection value, bottom layer tensile stress, and the minimum frost layer thickness were used as the checking indexes. The results of calculation and checking are shown in Table 10.

\subsection{Rationality and Verification of Porous Concrete Structure} Base. Although all pavement structures above can meet the requirements of the designed deflection value, allowable tensile stress calculation, and minimum frost layer thickness, a traditional pavement structure cannot be used to solve the water damage problem of asphalt pavement. According to the experiment analysis, the mechanical properties of porous concrete are excellent, and the material shows a superior drainage performance and frost resistance, which are helpful to solve the water damage problem $[52,53]$ and improve the service life of the pavement if the porous concrete is used as a pavement structure layer. Therefore, through an analysis of the mechanics and road performance of porous concrete, the proper connected porosity was chosen, with the appropriate modifications made based on the original design. Meanwhile, the feasibility of porous concrete used for the structural layer of asphalt pavement was analysed to provide help for the same types of projects.

6.2.1. Choices of Porosity of Porous Concrete under Pouring Rain Conditions. The east-west linear distance of the Inner Mongolia Autonomous Region is over $2,400 \mathrm{~km}$, and thus the amount of rainfall differs remarkably based on the topography, latitude, and other varying factors. There is a large amount of desert area with little rainfall, that is, less than $50 \mathrm{~mm}$, in the western area; the central area is mainly grassland with an annual rainfall of between 50 and $450 \mathrm{~mm}$; and the eastern part is affected by monsoons with significant rainfall of more than $500 \mathrm{~mm}$ annually. The precipitation in the area is mainly concentrated within the mideastern region with a maximum instantaneous rainfall of $33.7 \mathrm{~mm} / \mathrm{h}$, which is calculated as the ultimate rainfall intensity; thus, this region was regarded as the object of the present design study.

The rainwater infiltration is a top-to-bottom process. Natural precipitation is collected on the surface layer first, and apart from any natural loss, some of the rain flows away by road arching and other drainage facilities, and some seeps into the pavement structure through tiny openings or gaps.

Zhao [54] pointed out that the relationship between extreme rainfall intensity and the permeability coefficient can be expressed through the following formulae:

$$
W=\frac{4 K h i}{2+l}, \quad l=B \sqrt{1+\frac{i_{z}^{2}}{i_{h}^{2}}}
$$

where $W$ is the extreme rainfall intensity $(\mathrm{cm} / \mathrm{min}) ; K$ is the horizontal permeability coefficient of the drainage layer $(\mathrm{cm} / \mathrm{s}) ; h$ is the drainage layer thickness $(\mathrm{cm})$, with $10 \mathrm{~cm}$ chosen as the minimum design thickness; $l$ is the length of the drainage $(\mathrm{cm}) ; B$ is the width of the one-way slope pavement $(\mathrm{cm})$, considering one-half of the road, where $B$ is 7.5 and $m$ is $750 \mathrm{~cm}$; and $i_{z}$ and $i_{h}$ are the longitudinal and transverse gradients of the road surface, with $2 \%$ chosen for the calculations.

The design requirements can be satisfied only when the transverse permeability coefficient of the drainage layer is larger than the transverse permeability coefficient of the extreme rainfall intensity. Thus, changing the formula above can allow the relation between the transverse permeability coefficient and the extreme rainfall intensity to be obtained, as shown in the following:

$$
K \geq \frac{(2+l) W}{4 h i} .
$$

The calculation results show that smooth drainage under extreme conditions can be ensured when the horizontal permeability coefficient of the drainage layer is greater than 
TABLE 10: Summary of structural calculation and checking results of cement stabilized macadam base asphalt pavement.

\begin{tabular}{|c|c|c|c|c|}
\hline $\begin{array}{l}\text { Design deflection } \\
\text { value }(0.01 \mathrm{~mm})\end{array}$ & $\begin{array}{l}\text { Computed-deflection } \\
\text { values }(0.01 \mathrm{~mm})\end{array}$ & Structure layer appellation & $\begin{array}{c}\text { Allowable tensile } \\
\text { stress }(\mathrm{MPa})\end{array}$ & $\begin{array}{l}\text { Bottom tensile } \\
\text { stress }(\mathrm{MPa})\end{array}$ \\
\hline \multirow{3}{*}{21.7} & \multirow{3}{*}{21.1} & Coarse-graded bituminous concrete $(8 \mathrm{~cm})$ & 0.21 & -0.0561 \\
\hline & & Cement-stabilized macadam $(18 \mathrm{~cm})$ & 0.23 & 0.1377 \\
\hline & & $\begin{array}{l}\text { Cement-stabilized gravel mixed with crushed stone } \\
\qquad(32 \mathrm{~cm})\end{array}$ & 0.18 & 0.126 \\
\hline
\end{tabular}

TABLE 11: The possible frost-thawing cycle times of porous concrete in working environment.

\begin{tabular}{lcccc}
\hline $\begin{array}{l}\text { Goal } \\
\text { porosity } \\
(\%)\end{array}$ & $\begin{array}{c}\text { Annual average } \\
\text { temperature difference } \\
\text { of base }\left({ }^{\circ} \mathrm{C}\right)\end{array}$ & $\begin{array}{c}\text { The number of annual } \\
\text { freeze-thawing cycles that may } \\
\text { be experienced (times) }\end{array}$ & $\begin{array}{c}\text { The number of freeze-thawing cycles } \\
\text { that may be experienced during the } \\
\text { design period (times) }\end{array}$ & $\begin{array}{c}\text { The maximum number of } \\
\text { freeze-thawing cycles that } \\
\text { a porous concrete can stand } \\
\text { in design period (times) }\end{array}$ \\
\hline 15 & & & 765 & 780 \\
20 & 45 & 51 & 480 \\
25 & & & 420 \\
30 & & & 120 \\
\hline
\end{tabular}

$0.28 \mathrm{~cm} / \mathrm{min}$, which is clearly less than the measured permeability coefficient of porous concrete with a pavement cross slope of $2 \%$. Thus, in the pavement design, the connected porosity of the porous concrete can be $15 \%, 20 \%$, $25 \%$, or $30 \%$ under the natural local conditions.

6.2.2. Selection of Porosity of Porous Concrete under Cold Conditions. The average local temperature in winter annually is $-9^{\circ} \mathrm{C}$ to $-14^{\circ} \mathrm{C}$, and the average temperature in summer is $22^{\circ} \mathrm{C}$ to $26.4^{\circ} \mathrm{C}$. The altitude in eastern Inner Mongolia is high, and the varying temperature in the winter is generally low, which conforms to the characteristics of a cold climate. The average annual lowest temperature of about $-40^{\circ} \mathrm{C}$ appears in January, and the average annual highest temperature of about $30^{\circ} \mathrm{C}$ appears in July, which indicates that higher frost resistance of the porous concrete is required. Porous concrete is generally used as the base under the covering of the surface layer, the temperature shift of which is smaller and the working environment is better. A temperature field analysis $[55,56]$ indicated that in winter, when the air temperature is $-40^{\circ} \mathrm{C}$, the temperature of base is about $-27^{\circ} \mathrm{C}$, and in summer, when the air temperature is $30^{\circ} \mathrm{C}$, the base temperature is approximately $20^{\circ} \mathrm{C}$. The difference in yearly road surface temperature reaches $70^{\circ} \mathrm{C}$, and the yearly base temperature is $47^{\circ} \mathrm{C}$.

At present, the key to evaluating the frost resistance of concrete is to establish the relationship between the frost resistance testing and the actual work conditions. Based on an investigation of a typical city, the frost resistance of concrete has been quantitatively analysed $[57,58]$, and it was pointed out that the number of annual average freezethawing cycles in a concrete environment is closely related to the average temperature difference of the working environment. The ratio of indoor-to-outdoor freezethawing cycles is about $1: 12$, which indicates that the damage caused by the rapid freezing and thawing cycle in a room is equivalent to the damage caused by 12 freezethawing cycles in a natural environment. According to the
TABLE 12: Summary table of average strength of porous concrete.

\begin{tabular}{lcc}
\hline Goal porosity (\%) & $\begin{array}{c}7 \mathrm{~d} \text { compressive } \\
\text { strength }(\mathrm{MPa})\end{array}$ & $\begin{array}{c}\text { 28 d flexural tensile } \\
\text { strength }(\mathrm{MPa})\end{array}$ \\
\hline 15 & 8.3 & 1.60 \\
20 & 5.8 & 1.06 \\
25 & 3.5 & 0.64 \\
30 & 2.2 & 0.37 \\
\hline
\end{tabular}

above conclusions, the number of freeze-thawing cycles that may be experienced during the design period (15 years) of porous concrete can be calculated, as is shown in Table 11.

Table 11 shows that in the eastern region of Inner Mongolia, the annual mean temperature difference is large, and the number of freeze-thawing cycles that porous concrete may experience during the design period is 765 . According to the freezing and thawing cycle ratio of $1: 12$, the maximum frost resistance cycles of the porous concrete measured during laboratory testing should reach at least 63.7 to meet the actual requirements. Therefore, porous concrete with a goal porosity of $15 \%$ can be chosen as the pavement base.

6.2.3. Selection of Porous Concrete under Heavy Traffic Conditions. Based on laboratory testing and calculations, Zheng et al. [59] and Qiu et al. [60] pointed out the standard resistance compression and flexural tensile strength of a designed porous concrete base. The author's experiment data indicate that a $15 \%$ goal porosity of porous concrete can be used as pavement base under severely heavy traffic conditions; the average strength of porous concrete with each goal porosity is summarized in Table 12 .

Considering all the factors above, it is entirely reasonable to use porous concrete with a porosity of $15 \%$ as the base under heavy-load traffic in cold conditions, which can reduce the harm from water damage and ensure the safe operation of the pavement structure [61-64]. 


\section{Conclusion}

(1) Taking the aggregate tap density as an evaluation index, the gradation of porous concrete was determined using a stepwise filling method. Orthogonal testing was used to optimize the gradation of porous concrete, and the optimal combination scheme was determined based on the determination that the $\mathrm{w} / \mathrm{c}$ ratio has the largest effect on its performance. Moreover, the experiment results indicate that the linear relationship, independent of the age and specimen size, between the connected porosity and the goal porosity of porous concrete is excellent.

(2) In view of heavy-load traffic pavement in cold and heavy shower regions, the experiment analysed the drainage, the frost resistance, and shrinkage characteristics of porous concrete, and the results show that there is a certain function relationship between porous concrete's drainage, frost resistance, and connectivity porosity. In addition, porous concrete with a fine road performance has a better shrinkage characteristic than semirigid materials.

(3) The mechanical indexes of porous concrete, such as the compressive strength, flexural tensile strength, and compressive elastic modulus, were studied through mechanical tests, and the relation between the connected pores and mechanical indexes of porous concrete was analysed. The results indicate that there is a good linear relationship between the compressive strength, flexural tensile strength, compressive elastic modulus, and connected porosity.

(4) Considering the characteristics of the Inner Mongolian climate, the feasibility of using porous concrete in cold and heavy shower regions was analysed. By comparing the performance with the mechanics of porous concrete, a goal porosity of $15 \%$ in porous concrete pavement can be used for heavy traffic conditions. Thus, porous concrete as an asphalt pavement base can meet the requirements of heavyload traffic regions under heavy shower conditions.

\section{Conflicts of Interest}

The authors declare that there are no conflicts of interests regarding the publication of this paper.

\section{Acknowledgments}

This work is financially supported by the Special Fund for Basic Scientific Research of Central Colleges of Chang'an University (Grant nos. 310821173312, 310821165011, and 310821172004) and the National Key R\&D Program of China (no. 2017YFC0805306).

\section{References}

[1] J. Judycki, "Determination of equivalent axle load factors on the basis of fatigue criteria for flexible and semi-rigid pavements," Road Materials \& Pavement Design, vol. 11, no. 1, pp. 187-201, 2010.

[2] J. X. Lai, K. Y. Wang, J. L. Qiu et al., "Vibration response characteristics of the cross tunnel structure," Shock and Vibration, vol. 2016, Article ID 9524206, 16 pages, 2016.

[3] Z. Q. Zhang, X. Q. Shi, B. Wang, and H. Y. Li, "Stability of NATM tunnel faces in soft surrounding rocks," Computers and Geotechnics, 2017, In press.

[4] R. A. Tarefder and M. Ahmad, "Evaluation of pore structure and its influence on permeability and moisture damage in asphalt concrete," International Journal of Pavement Engineering, vol. 18, no. 3, pp. 274-283, 2015.

[5] J. X. Lai, H. B. Fan, J. X. Chen et al., "Blasting vibration monitoring of undercrossing railway tunnel using wireless sensor network," International Journal of Distributed Sensor Networks, vol. 2015, Article ID 703980, 7 pages, 2015.

[6] J. X. Lai, J. L. Qiu, H. B. Fan et al., "Fiber bragg grating sensors-based in-situ monitoring and safety assessment of loess tunnel," Journal of Sensors, vol. 2016, Article ID 8658290 , 10 pages, 2016.

[7] H. J. Zhang, Z. Z. Wang, F. Lu, G. Y. Xu, and W. G. Qiu, "Analysis of the displacement increment induced by removing temporary linings and corresponding countermeasures," Tunnelling and Underground Space Technology, vol. 73, pp. 236-243, 2018.

[8] B. J. Putman and A. I. Neptune, "Comparison of test specimen preparation techniques for pervious concrete pavements," Construction \& Building Materials, vol. 25, no. 8, pp. 3480-3485, 2011.

[9] Q. X. Yan, H. Chen, W. Y. Chen, J. C. Zhang, and X. Huang, "Dynamic characteristic and fatigue accumulative damage of a cross shield tunnel structure under vibration load," Shock and vibration, vol. 2018, Article ID 9525680, 14 pages, 2018.

[10] Q. X. Yan, B. J. Li, Z. X. Deng, and B. Li, "Responses of shield tunnel structures with and without secondary lining," Structural Engineering and Mechanics, 2018, In press.

[11] Z. F. Wang, S. L. Shen Jack, W. C. Cheng, and A. Arulrajah, "Simple method to predict ground displacements caused by installing horizontal jet-grouting columns," Mathematical Problems in Engineering, vol. 2018, Article ID 1897394, 11 pages, 2018.

[12] J. X. Lai, X. L. Wang, J. L. Qiu et al., “A state-of-the-art review of sustainable energy based freeze proof technology for coldregion tunnels in China," Renewable and Sustainable Energy Reviews, vol. 82, pp. 3554-3569, 2018.

[13] J. X. Lai, S. Mao, J. L. Qiu et al., "Investigation progresses and applications of fractional derivative model in geotechnical engineering," Mathematical Problems in Engineering, vol. 2016, Article ID 9183296, 15 pages, 2016.

[14] J. X. Lai, H. Q. Liu, J. L. Qiu, and J. X. Chen, "Settlement analysis of saturated tailings dam treated by CFG pile composite foundation," Advances in Materials Science and Engineering, vol. 2016, Article ID 7383762, 10 pages, 2016.

[15] X. L. Du, L. Jin, and G. W. Ma, "Macroscopic effective mechanical properties of porous dry concrete," Cement \& Concrete Research, vol. 44, no. 1, pp. 87-96, 2013.

[16] J. S. Chen, C. T. Lee, and Y. Y. Lin, "Influence of engineering properties of porous asphalt concrete on long-term performance," Journal of Materials in Civil Engineering, vol. 29, no. 4, 2017.

[17] J. X. Lai, H. Zhou, K. Wang et al., "Shield-driven induced ground surface and Ming Dynasty city wall settlement of Xi' an metro," Tunnelling and Underground Space Technology, 2018, In press. 
[18] J. X. Lai, S. Y. He, J. L. Qiu et al., "Characteristics of earthquake disasters and aseismic measures of tunnels in Wenchuan earthquake," Environmental Earth Sciences, vol. 76, no. 2, pp. 76-94, 2017.

[19] J. San, "Strength criterion for ecological light porous concrete under multiaxial stress," Construction \& Building Materials, vol. 44, pp. 663-670, 2013.

[20] J. Drake, A. Bradford, and T. Van Seters, "Winter effluent quality from partial-infiltration permeable pavement systems," Journal of Environmental Engineering, vol. 140, no. 11, 2014.

[21] J. X. Lai, X. L. Wang, J. L. Qiu, J. X. Chen, Z. N. Hu, and H. Wang, "Extreme deformation characteristics and countermeasures for a tunnel in difficult grounds in southern Shaanxi, China," Environmental Earth Sciences, 2018, In press.

[22] J. X. Lai, J. L. Qiu, H. B. Fan, J. X. Chen, and Y. L. Xie, "Freezeproof method and test verification of a cold region tunnel employing electric heat tracing," Tunnelling and Underground Space Technology, vol. 60, pp. 56-65, 2016.

[23] M. L. Zheng, "Permeability coefficient and test method of porous concrete," Journal of Traffic and Transportation Engineering, 2006.

[24] C. B. Jiang, "Study on the characteristic of pore in porous concrete," Journal of the Chinese Ceramic Society, vol. 34, no. 4, pp. 1105-1110, 2015.

[25] Q. Yang and X. J. Wen, "Mixture design of plastic porous cement concrete for urban highway base," Journal of Tongji University, vol. 38, no. 6, pp. 850-853, 2010.

[26] J. L. Qiu, H. Q. Liu, J. X. Lai, H. P. Lai, J. X. Chen, and $\mathrm{K}$. Wang, "Investigating the long term settlement of a tunnel built over improved loessial foundation soil using jet grouting technique," Journal of Performance of Constructed Facilities, 2018.

[27] X. B. Yan, C. C. Gong, S. D. Wang, and L. C. Lu, "Effect of aggregate coating thickness on pore structure features and properties of porous ecological concrete," Magazine of Concrete Research, vol. 65, no. 16, pp. 962-969, 2013.

[28] JTG E42-2005, Test Methods of Aggregate for Highway Engineering, People's Communications Press, Beijing, China, 2005.

[29] JTG E30-2005, Test Methods of Cement and Concrete for Highway Engineering, People's Communications Press, Beijing, China, 2005.

[30] Z. F. Yang, W. Ma, W. G. Shen, and M. K. Zhou, "The aggregate gradation for the porous concrete pervious road base material," Journal of Wuhan University of TechnologyMaterials Science Edition, vol. 23, no. 3, pp. 391-394, 2008.

[31] J. L. Qiu, Y. L. Xie, H. B. Fan, Z. C. Wang, and Y. W. Zhang, "Centrifuge modelling of twin-tunnelling induced ground movements in loess strata," Arabian Journal of Geosciences, vol. 10, p. 493, 2017.

[32] J. L. Qiu, Z. C. Wang, J. X. Lai, Q. Zhang, and J. B. Wang, "Response characteristics and preventions for seismic subsidence of loess in Northwest China," Natural Hazards, 2018.

[33] L. Q. Hu, A. M. Sha, and S. S. Zhang, "Design method of nofines porous concrete composition based on vibration compaction," Journal of Traffic \& Transportation Engineering, vol. 12, no. 2, pp. 1-9, 2012.

[34] W. Ma, Study on the Design of Porous Concrete Pervious Base, Ph.D. thesis, Wuhan University of Technology, China, 2008.

[35] J. X. Lai, Z. H. Feng, J. L. Qiu et al., "In-situ test of grouting reinforcement for water-enriched sandy gravel ground in river floodplain," Advances in Materials Science and Engineering, vol. 2016, Article ID 2129659, 12 pages, 2016.
[36] M. Valcuende, C. Parra, E. Marco et al., "Influence of limestone filler and viscosity-modifying admixture on the porous structure of self-compacting concrete," Construction \& Building Materials, vol. 28, no. 1, pp. 122-128, 2012.

[37] JTG E51-2009, Test Methods of Materials Stabilized with Inorganic Binders for Highway Engineering, People's Communications Press, Beijing, China, 2009.

[38] M. L. Zheng, S. F. Chen, and B. G. Wang, "Mixture ratio design method of porous concrete based on orthogonality test," Journal of Tongji University, vol. 34, no. 10, pp. 13191323, 2006.

[39] W. D. Martin, B. J. Putman, and N. B. Kaye, "Using image analysis to measure the porosity distribution of a porous pavement," Construction \& Building Material, vol. 48, pp. 210-217, 2013.

[40] W. Jiang, A. M. Sha, J. J. Xiao, and Z. J. Wang, "Microscopic void features and influence of porous asphalt concrete," Journal of Tongji University, vol. 43, no. 1, pp. 67-74, 2015.

[41] J. J. Xiao, A. M. Sha, W. Jiang, and Z. J. Wang, "Study on the pavement performance of porous asphalt concrete," Journal of Wuhan University of Technology, vol. 35, no. 4, pp. 49-53, 2013.

[42] R. Zhong and K. Wille, "Material design and characterization of high performance pervious concrete," Construction \& Building Materials, vol. 98, pp. 51-60, 2015.

[43] C. Lian and Y. Zhuge, "Optimum mix design of enhanced permeable concrete-an experimental investigation," Construction \& Building Materials, vol. 24, no. 12, pp. 2664-2671, 2010.

[44] W. Wan, Preparation of Water Permeable Ecological Concrete and Study of Its Frost Resistance, Ph.D. thesis, Jiangsu University, China, 2006.

[45] W. Jiang, A. M. Sha, J. J. Xiao, and R. Li, "Prediction model of air void content for porous asphalt concrete," Journal of Wuhan University of Technology, vol. 33, no. 11, pp. 55-59, 2011.

[46] S. Hatanaka, N. Mishima, T. Nakagawa et al., "Finishing methods and compressive strength-void ratio relationships of in-situ porous concrete pavement," Computers \& Concrete, vol. 10, no. 3, pp. 231-240, 2012.

[47] X. Q. Li, Y. M. Hou, and X. Y. Gu, "Study on the effect factors of mechanical properties of porous cement concrete," Journal of Nanjing Forestry University, vol. 32, no. 4, pp. 113-115, 2008.

[48] C. Lian, Y. Zhuge, and S. Beecham, "The relationship between porosity and strength for porous concrete," Construction \& Building Materials, vol. 25, no. 11, pp. 4294-4298, 2011.

[49] H. K. Kin and H. K. Lee, "Influence of cement flow and aggregate type on the mechanical and acoustic characteristics of porous concrete," Applied Acoustics, vol. 71, no. 7, pp. 607-615, 2010.

[50] T. Gabet, H. Benedetto, D. Perraton et al., "French wheel tracking round robin test on a polymer modified bitumen mixture," Materials \& Structures, vol. 44, no. 6, pp. 1031-1046, 2011.

[51] J. Visscher and A. Vanelstraete, "Ravelling by traffic: performance testing and field validation," International Journal of Pavement Research \& Technology, vol. 10, no. 1, pp. 54-61, 2017.

[52] M. Bhutta, K. Tsuruta, and J. Mirza, "Evaluation of highperformance porous concrete properties," Construction \& Building Materials, vol. 31, no. 6, pp. 67-73, 2012.

[53] Y. P. Sheng, S. F. Chen, and H. B. Li, "Research of road performance of porous concrete with non-vibration 
molding," Journal of Hebei University of Technology, vol. 36, no. 6, pp. 99-105, 2007.

[54] Y. G. Zhao, Study on Frost Resistance and Construction Control of Semi-Rigid Base, Ph.D. thesis, Chang'an University, Xi'an, China, 2013.

[55] T. Y. Sun, Study on the Structure and Material of Porous Cement Macadam Drainage Base, Ph.D. thesis, Chang'an University, Xi'an, China, 2013.

[56] W. H. Zhou, H. Y. Qin, J. L. Qiu et al., "Building information modelling review with potential applications in tunnel engineering of China," Royal Society Open Science, vol. 4, no. 8, 2017.

[57] G. Al-Assadi, M. J. Casati, J. Fernandez, and J. C. Galvez, "Effect of the curing conditions of concrete on the behaviour under freeze-thaw cycles," Fatigue \& Fracture of Engineering Materials \& Structures, vol. 34, no. 7, pp. 461-469, 2011.

[58] Y. W. Zhang, J. X. Lai, and Y. L. Xie, "Modelling spatial and temporal characteristics of FHF in a cold region tunnel," Journal of Cold Regions Engineering, 2018, In press.

[59] M. L. Zheng, S. F. Chen, and B. G. Wang, "Study on the shrinkage character of porous concrete," Journal of Xi'an University of Architecture \& Technology, vol. 37, no. 4, pp. 483-487, 2005.

[60] J. L. Qiu, X. L. Wang, S. He et al., "The catastrophic landside in Maoxian County, Sichuan, SW China, on June 24, 2017," Natural Hazards, vol. 3, no. 1-9, 2017.

[61] W. C. Cheng, J. C. Ni, A. Arulrajah, and H. W. Huang, "A simple approach for characterising tunnel bore conditions based upon pipe jacking data," Tunnelling and Underground Space Technology, vol. 71, pp. 494-504, 2018.

[62] Z. F. Wang, X. Bian, and Y. Q. Wang, "Numerical approach to predict ground displacement caused by installing a horizontal jet grout column," Marine Georesources and Geotechnology, vol. 35, no. 7, pp. 970-977, 2017.

[63] Y. Li, Y. Yang, H. Yu, and G. Roberts, "Principal stress rotation under bidirectional simple shear loadings," KSCE Journal of Civil Engineering, vol. 1, no. 1-10, 2018.

[64] X. Z. Li, C. Z. Qi, and Z. S. Shao, "A microcrack growth-based constitutive model for evaluating transient shear properties during brittle creep of rocks," Engineering Fracture Mechanics, vol. 194, pp. 9-23, 2018. 


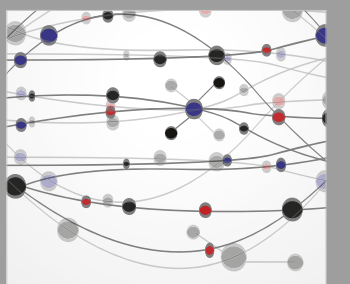

The Scientific World Journal
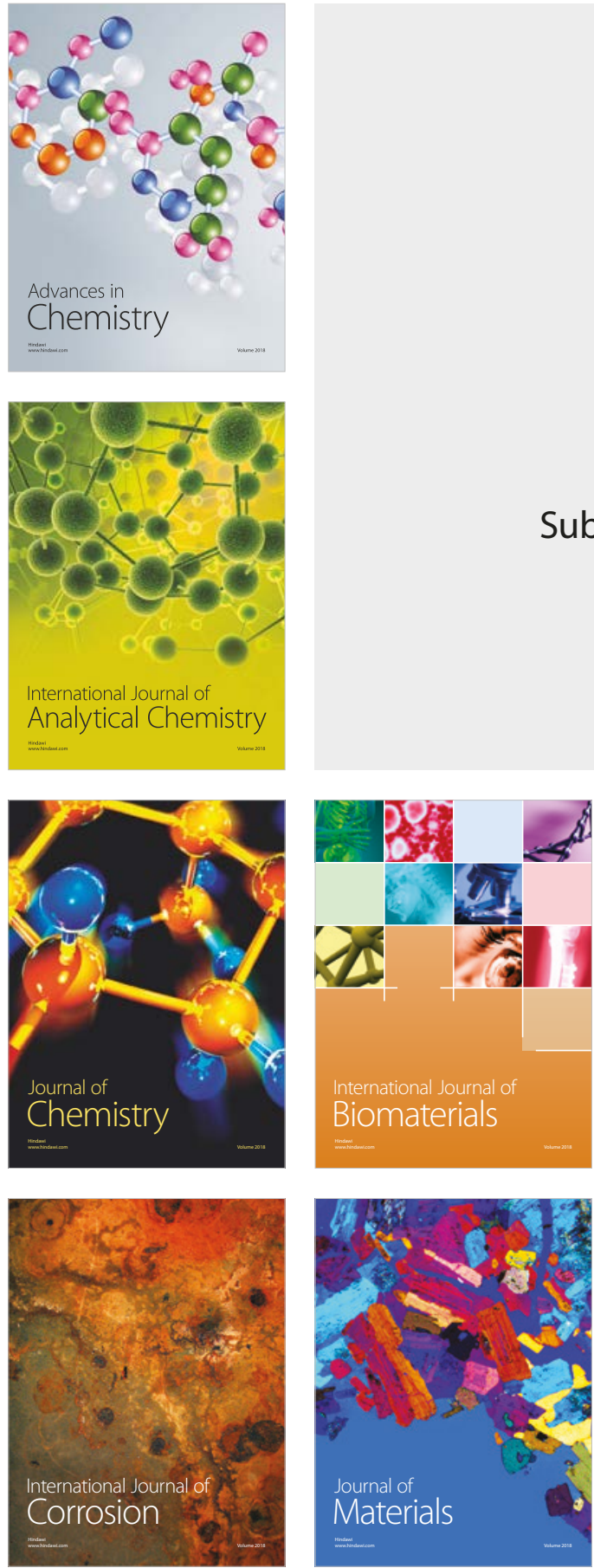

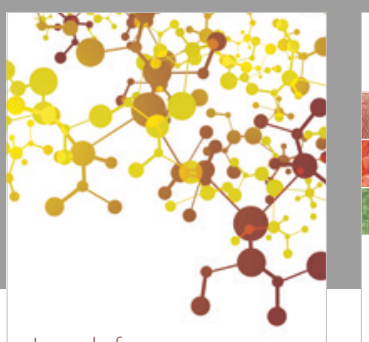

Journal of

Applied Chemistry
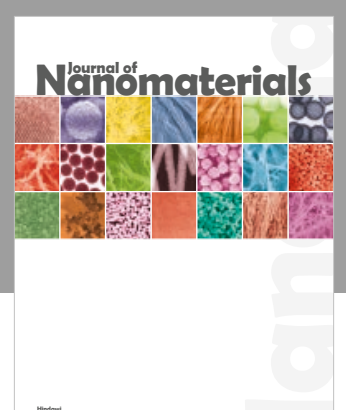

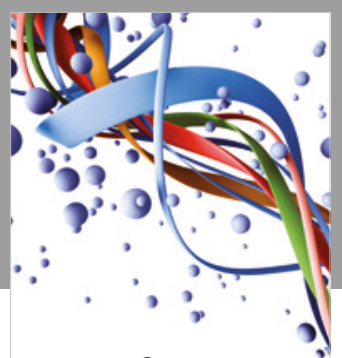

Scientifica

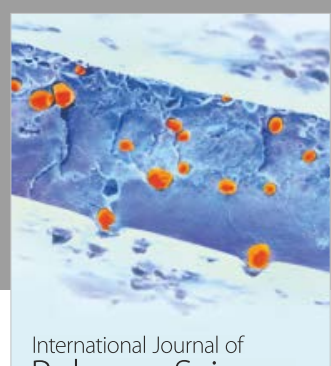

Polymer Science

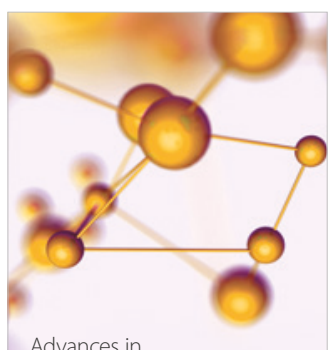

Physical Chemistry
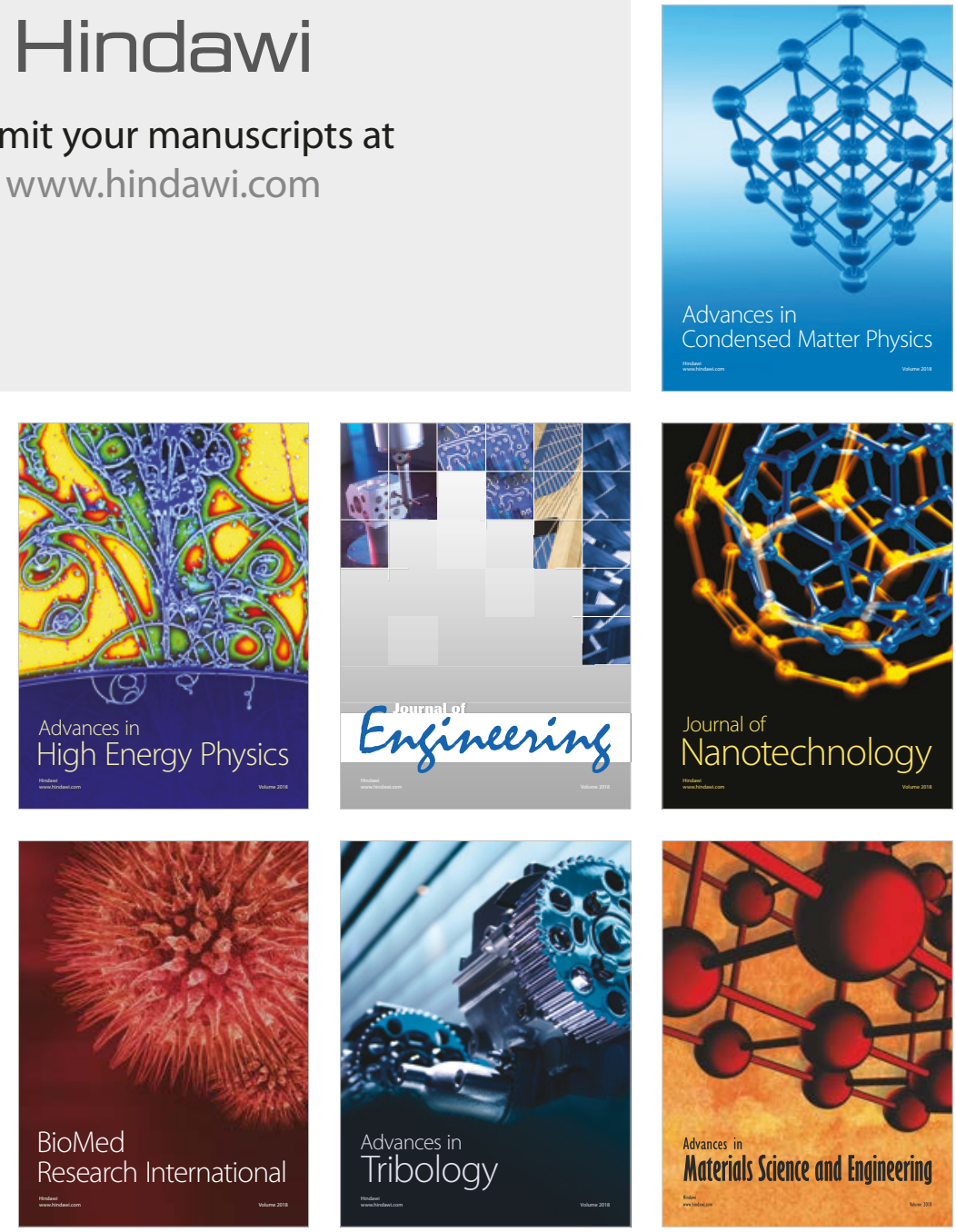